\title{
SUPPLY-SIDE ECONOMICS \\ IN A GLOBAL ECONOMY
}

\author{
Enrique G. Mendoza \\ Linda L. Tesar
}

Working Paper No. 5086

\section{NATIONAL BUREAU OF ECONOMIC RESEARCH 1050 Massachusetts Avenue \\ Cambridge, MA 02138 April 1995}

We thank Tom Cooley, Michael Devereux, Jeremy Greenwood, Dale Henderson, Robert King, Sergio Rebelo, Assaf Razin, and Alan Stockman for helpful suggestions and comments. This paper is part of NBER's research program in International Finance and Macroeconomics. Any opinions expressed are those of the authors and not those of the Board of Governors of the Federal Reserve System or the National Bureau of Economic Research.

(C) 1995 by Enrique G. Mendoza and Linda L. Tesar. All rights reserved. Short sections of text, not to exceed two paragraphs, may be quoted without explicit permission provided that full credit, including $\odot$ notice, is given to the source. 


\title{
SUPPLY-SIDE ECONOMICS
}

\section{IN A GLOBAL ECONOMY}

\begin{abstract}
Recent quantitative studies predict large welfare gains from reducing tax distortions in a closed economy, despite costly transitional dynamics to more efficient tax systems. This paper examines transitional dynamics and gains of tax reforms for countries in a global economy, and provides numerical solutions for international tax competition games. Tax reforms in a global economy cause cross-country externalities through capital flows in response to consumptionsmoothing and debt-servicing effects, with taxes on world payments affecting the distribution of welfare gains. Within the class of time-invariant tax rates, the gains of replacing income taxes with consumption taxes are large and, in the absence of taxes on foreign assets, the monopoly distortion separating cooperative and noncooperative equilibria is negligible. The analysis starts from a benchmark reflecting current G-7 fiscal policies, and considers the effects of tax reforms on real exchange rates and interest differentials. Tax-distorted equilibrium dynamics are computed using a modified version of the King-Plosser-Rebelo algorithm augmented with shooting routines.
\end{abstract}

Enrique G. Mendoza

International Finance Division

Board of Governors of the Federal Reserve System

Washington, DC 20551
Linda L. Tesar

Department of Economics

University of California-Santa Barbara

Santa Barbara, CA 93106

and NBER 
"Quantitative welfare economics, seriously practiced, can be a discouraging business. The supply side economists, if that is the right term for those whose research I have been discussing, have delivered the largest genuinely free lunch I have seen in 25 years in the business, and I believe we would have a better society if we followed their advice." [Robert E. Lucas Jr., (1990), p.314]

"In this town (Washington), nothing is certain but death and tax reform...Enthusiasm for revamping the tax code--this time to encourage Americans to save and businesses to invest--once was limited to academics who spend their lives contemplating the perfect tax. Now it is spilling over to politicians" [Wall Street Journal, 2/1/95, p.A1]

\section{1.- Introduction}

Robert Lucas' (1990) seminal lecture on supply-side economics highlighted the potential for farreaching tax reforms to produce large social welfare gains in the context of a neoclassical dynamic equilibrium model of a closed economy. His analysis suggested that by replacing the capital income tax with a higher tax on labor income, as prescribed by basic optimal taxation principles (see Chamley (1981) and (1986)), the trend level of consumption per capita in the United States could be increased by about 1 percent. This figure includes a rough estimate of the cost of the transitional dynamics that society incurs in the process of expanding the capital stock from the lower level implied by a heavily tax-distorted economy to the level consistent with a more efficient tax system. In the spirit of Lucas' work, other studies, such as Baxter and King (1993), Chari, Christiano, and Kehoe (1994), Cooley and Hansen (1992), Greenwood and Huffman (1991), King and Rebelo (1990), Jones, Manuelli, and Rossi (1993), and Rebelo (1991), examined welfare, business cycle, and growth implications of tax reforms, including Ramsey's optimal taxation problem. These studies are consistent with Lucas' findings in suggesting that a well-conceived tax reform can improve the economy's saving, investment, and growth rates and result in sizable welfare gains. Moreover, these gains are of such magnitude that the gains of other major policy endeavors, such as output and price stabilization, seem negligible.

The aim of this paper is to examine the macroeconomic effects of tax reforms from the perspective of an open economy with fully integrated capital and goods markets.' The analysis emphasizes two issues. First, the implications of international asset trading for the quantification of positive and normative effects of tax reforms. This is important because in the closed- economy models examined to date households have no choice but to finance the accumulation of capital during the transition following a tax reform by

'In a recent study, Arvanitis (1994) conducts a quantitative examination of capital income taxation in a two-country model. His analysis abstracts from normative issues and does not address the closed-form indeterminacy of the stationary equilibrium in the tax-distorted two-country model. 
sacrificing consumption. Consequently, transitional dynamics are characterized by an initial stage of declining, or slow rising, consumption and rising investment, with an adverse effect on welfare. The welfare cost of these transitional dynamics is substantial and can easily outweigh the benefits of policies that may seem optimal from a purely steady-state perspective. These results may not apply to an open economy because households can turn to world capital markets to finance the transition. This alters both the pattern of adjustment of macroeconomic variables--with the current account partially absorbing the cost of the transition--and the magnitude of the net welfare gain resulting from a tax reform.

Tax reforms also induce international externalities because they affect economic activity and welfare worldwide by altering the profile of borrowing and lending across countries and the equilibrium world real interest rate. ${ }^{2}$ Thus, the second issue that the paper addresses is the quantitative analysis of international tax competition games that highlight the implications of these global externalities. There is a large literature examining the international transmission mechanisms that provide incentives for strategic behavior on the part of fiscal authorities and the nature of the equilibria that this behavior produces. ${ }^{3}$ However, despite the fact that the suboptimality of noncooperative equilibria is a common theme in this literature, there have been few attempts to show whether the international externalities that distort the equilibria are of sufficient magnitude to justify the global coordination of tax policies.

This paper is also motivated by major fiscal policy reforms currently being debated in several industrial countries. The heated debates on tax reform proposals and on methods used for assessing their budgetary implications in the U.S. Congress, on deficit reduction in Japan and the United States, and on public debt and tax convergence in the European Union, envisage radical structural changes in tax structures and rules governing current expenditures and transfer payments. In light of the high degree of integration of capital markets across these countries, and the opening of financial markets in several developing

${ }^{2}$ Frenkel and Razin (1987) provide a comprehensive analysis of international spillovers of tax policies.

${ }^{3}$ See for example, Backus, Devereux, and Purvis (1988), Bovenberg (1989), Buiter and Kletzer (1991), Calvo and Obstfeld (1988), Chari and Kehoe (1990), Correia (1992), Frenkel and Razin (1987), Frenkel, Razin, and Sadka (1990), Kehoe (1987), Obstfeld and Rogoff (1994), Razin and Sadka (1989) and (1991), and Sibert (1990). Some of these studies focus on efficiency gains in representative-agent models and others focus on distributional effects and time-inconsistency in overlapping-generations settings. Our paper is in the first vein. 
economies, the quantitative analysis of fiscal reforms in a global economy is critical in order to provide accurate assessments for these policy discussions.

Our analysis adopts Feldstein's (1976) interpretation of "tax reforms" as those that start from actual tax systems and recognize that reforms are slow and piecemeal, in contrast with "tax design" as implied by solutions to Ramsey optimal taxation problems. In Feldstein's view, the complexity of these optimal tax strategies makes them impractical and politically inviable. For the quantitative experiments, we also follow Harberger's (1964) "nth-best" principle not to emphasize Pareto-optimal or even second-best solutions, but to focus instead on measures of welfare costs associated with the economy being in any given distorted equilibrium. Therefore, we restrict our study to suboptimal tax reforms within the class of time-invariant, distortionary tax rates, as in Lucas (1990) and Cooley and Hansen (1992). These tax reforms are nevertheless consistent with Ramsey's (1927) tradition in that they satisfy the optimality conditions of the intertemporal competitive equilibrium and finance a pre-determined path of government expenditures. In contrast to a typical Ramsey problem, however, government debt or transfers are set to meet a predetermined long-run target. ${ }^{4}$ In summary, the methodology we follow shares Lucas' (1990) objectives of (a) finding tax rates that maximize welfare, consistent with a given government expenditure policy and market-determined prices and quantities, and (b) providing a quantitative assessment of the benefits of reforming actual tax systems in this direction.

We conduct the analysis in the context of a two-sector, two-country model of a global economy described in Section 2. The model extends the business cycle model of Stockman and Tesar (1995) by introducing government expenditures and transfers financed by distortionary taxes on factor incomes and consumption. The sectoral disaggregation allows us to examine transitional dynamics of real exchange rates and interest rate differentials induced by tax reforms, which are important to consider given the inability of macroeconomic models to explain the dynamics of these variables (see Froot and Rogoff (1995)), and the key role they play in policy decisions. The model also deviates from the Stockman-Tesar framework in that,

\footnotetext{
${ }^{4}$ In fact, if government expenditures and transfers are kept constant relative to the size of the economy, we prove that there is an optimal time-invariant tax structure that recreates the first-best social optimum.
} 
because of tax distortions, the competitive equilibrium does not coincide with the solution to a world planner's problem. The equilibrium is instead solved directly under the assumption that world asset trading is limited to one-period bonds. This asset structure allows the model to support observed cross-country differences in capital income tax rates in a steady-state, balanced-growth competitive equilibrium.

For the quantitative analysis of tax reforms to be useful in policy discussions, in the spirit of Lucas' objectives, it is critical to begin with an accurate description of current fiscal policies. The analysis also requires a reliable method to characterize the transitional dynamics of the open economy, so as to deal appropriately with intertemporal equilibrium interactions between macroeconomic variables. ${ }^{5}$ These two key methodological problems are addressed here as follows. First, the model's pre-reform equilibrium is calibrated to reflect the current stance of fiscal policies in G-7 countries following recent work on measurement of effective tax rates by Mendoza, Razin, and Tesar (1994). Second, intertemporal equilibrium allocations are computed numerically using a variant of the linear approximation method of King, Plosser, and Rebelo (1988) modified to address the closed-form indeterminacy of steady-state allocations in a taxdistorted, two-country model. In effect, this combines the KPR method with the shooting methods suggested by Lipton et al. (1982) and Lipton and Sachs (1983).

Section 3 provides assessments of basic tax reforms. The analysis starts with an assessment of the overall social costs of tax distortions by examining the welfare gains implied by a shift from current tax policies to social optimum policies. Since the magnitude of potential welfare gains and the tax structure in the social optimum depend largely on the assumed behavior of government expenditures, we consider two government expenditure rules. The first is a relative rule according to which expenditures are kept constant relative to the size of the economy, and the second is an absolute rule under which real expenditures are kept at a constant level. Then, since social optimum policies are unrealistic because they have implicit some form of lump-sum taxation, we proceed to impose absolute and relative constraints on government transfers and turn our attention to tax reforms limited to distortionary taxes. We consider the effects of unilateral and

\footnotetext{
${ }^{5}$ Concern for the manner in which dynamic scoring methods for budget planning in some policy circles address this issue has prompted a heated political debate in the United States.
} 
global tax reforms setting factor income taxes at the rates indicated by the social optimum, but using consumption taxes instead of lump-sum taxes to finance transfers and expenditures. ${ }^{6}$ These experiments also examine closed-economy variants to isolate the effects of international asset trading, and to compare results with those in Lucas (1990) and Cooley and Hansen (1992).

We find that transitional dynamics and the size of welfare gains are substantially different for open economies relative to closed economies, and that taxes on foreign interest income affect the cross-country distribution of those gains. In general, the results illustrate the extent to which world financial markets allow households to spread the costs of transitional dynamics intertemporally, and provide a vehicle for sharing the costs and benefits of tax reforms with the rest of the world. While Lucas' result that sound tax reforms produce large welfare gains remains unaltered, it is not necessarily true that there is a "genuinely free lunch" for everybody. Through international externalities via debt accumulation and real exchange rate and interest rate dynamics, there are situations in which part of the home (foreign) welfare gain is at the expense of the foreign (home) country. International transmission during a tax reform works through two effects: (1) a smoothing effect, as a country borrows from abroad to finance the initial stages of transitional investment, and (2) a long-run income-redistribution effect, resulting from net interest payments on the new steady-state foreign asset position to which a country converges. In addition, under the relative rule for government expenditures, there are large adverse wealth effects induced by the rise of government expenditures in response to output growth.

Section 4 examines international tax competition games that highlight differences between cooperative and noncooperative tax reforms. This analysis considers strategic adjustments to direct and indirect tax rates, and studies the degree of market power that a country exerts to alter world relative prices in its favor. We compute Nash and Stackelberg equilibria for a tax competition game in which each country takes into account the pattern of transitional dynamics starting from current tax policies under alternative tax strategies. The noncooperative solutions are compared to a cooperative solution based on an additive

${ }^{6}$ This tax reform shares features of tax reform proposals by the Chairman of the Ways and Means Committee, Sen. William Archer, who supports a consumption-only tax system, and by the Chairman of the Senate Budget Committee, Sen. Pete Domenici, who supports the Unlimited Savings Allowance tax system. 
world welfare function. Because of the presence of a monopoly-like distortion in the manner in which noncooperative fiscal authorities treat world prices, Nash and Stackelberg equilibria are dominated by the Cooperative solution that requires global tax coordination. However, the numerical analysis shows that, in the absence of taxes on foreign bonds, international externalities do not produce substantial differences between Nash, Stackelberg, and Cooperative equilibria. This is reflected in the steepness of the reaction curves and in the negligible differences in pay-offs between the three equilibria. The result suggests then that while the overall benefits of tax reforms are large, the incremental gain obtained by internalizing international spillovers through global cooperation are minimal. Thus, the model is in line with Frenkel, Razin, and Sadka (1993), which examine cases where noncooperative and cooperative equilibria coincide, although it embodies some of the incentives for strategic behavior emphasized by Chari and Kehoe (1990) and Kehoe (1987). In contrast, when there are taxes on world payments, noncooperative solutions become increasingly suboptimal. We conclude, therefore, that world tax coordination, either to eliminate taxes on world payments or to coordinate domestic tax rates, is required to maximize world welfare.

\section{A Two-Country, Two-Sector Model for Fiscal Policy Analysis}

\subsection{Households, Firms, the Public Sector and Market Clearing}

\section{Households}

Consider a two-country world in which each country produces a good that is traded internationally and a nontraded good for domestic use. Households in the home country maximize lifetime utility over consumption of traded and nontraded goods $\left(C^{T}\right.$ and $C^{N}$, respectively) and leisure $\left(L_{\imath}\right)$ subject to a lifetime budget constraint. Foreign households face an analogous problem. The presentation is based on homecountry decisions, and, when needed, foreign-country decisions are incorporated using asterisks to denote foreign variables. Lifetime utility is given by:

$$
\sum_{i=0}^{\infty} \beta^{t} \cup\left(C_{t}^{T}, C_{t}^{N}, L_{t}\right)
$$

and the instantaneous utility function is:

$$
U\left(C_{t}^{T}, C_{t}^{N}, L_{t}\right)=\left(\frac{1}{1-\sigma}\right)\left\{\left[\left(C_{t}^{T}\right)^{-\mu} \cdot\left(C_{t}^{N}\right)^{-\mu}\right]^{-\frac{1}{\mu}} L_{t}^{a}\right\}^{1-\sigma}
$$


With the price of traded goods as the numeraire, the date-t budget constraint faced by households is:

$$
\begin{array}{r}
\left(1+\tau_{c}\right)\left(C_{t}^{T}+p_{t}^{N} C_{t}^{N}\right)=\left(1-\tau_{n}\right)\left[\omega_{t}^{T} N_{t}^{T}+p_{t}^{N} \omega_{t}^{N} N_{t}^{N}\right]+\left(1-\tau_{k}\right)\left[\left(r_{t}^{T}-8\right) K_{t}^{T}+p_{t}^{N}\left(r_{t}^{N}-\delta\right) K_{t}^{N}\right] \\
-\gamma\left[K_{t+1}^{T}+p_{t}^{N} K_{t+1}^{N}\right]+(1-8)\left[K_{t}^{T}+p_{t}^{N} K_{t}^{N}\right]-\Psi\left(K_{t}^{T}, I_{t}^{T}\right)-\Psi\left(K_{t}^{N}, I_{t}^{N}\right) \\
-\gamma\left(1+\tau_{b}\right) R_{t} B_{t+1}+B_{t}+T_{t}^{T}+p_{t}^{N} T_{t}^{N}
\end{array}
$$

Households take policy variables and relative prices as given. The left-hand-side of (9) is the post-tax value of consumption in units of tradables; $\mathbf{p}_{t}{ }_{t}$ is the relative price of nontradables and $\tau_{c}$ is consumption a tax. The right-hand-side is the disposable income available for consumption obtained by deducting from post-tax factor income expenses on capital accumulation and net foreign interest payments, and adding net government transfer payments. Post-tax labor income is derived from labor supplied to traded and nontraded industries, $\mathrm{N}^{\mathrm{T}}{ }_{\mathrm{t}}$ and $\mathrm{N}^{\mathrm{N}}{ }_{\mathrm{t}}$, at pre-tax real wage rates $\mathrm{w}_{\mathrm{t}}^{\mathrm{T}}$ and $\mathrm{w}^{\mathrm{N}}{ }_{\mathrm{p}}$ and taxed uniformly at rate $\tau_{\mathrm{n}}$. Similarly, posttax capital income is derived from capital supplied to traded and nontraded sectors, $\mathrm{K}^{\mathrm{T}}$ and $\mathrm{K}^{\mathrm{N}}$, at pre-tax real rates $r^{\mathrm{T}}$ and $\mathrm{r}^{\mathrm{N}}$, and taxed uniformly at rate $\tau_{\mathrm{k}}$ with an allowance for depreciation (the depreciation rate is 8$)^{7}$ This allowance is common practice in the tax codes of G-7 countries.

As owners of firms, households also incur expenses related to capital-accumulation. As in King, Plosser, and Rebelo (1988) and the benchmark model in Lucas (1990), we assume that economic growth is driven by exogenous labor-augmenting technical progress at a common world rate $\gamma^{8}{ }^{8}$ This implies that a stationary transformation of investment expenditures in sector $i$, for $\mathrm{i}=\mathrm{T}, \mathrm{N}$, is given by $\mathrm{I}_{\mathrm{t}}^{\mathrm{i}}=\gamma \mathrm{K}_{\mathrm{t}+1}^{\mathrm{i}}-(1-\delta) \mathrm{K}_{\mathrm{t}}^{\mathrm{i}},{ }^{9}$ Moreover, to be consistent with the findings of international RBC models, which show that physical and financial capital must be imperfect substitutes for investment dynamics to be realistic (Mendoza (1991)),

7 This specification implies that domestic households do not own shares in foreign capital, which allows the model to support a long-run, balanced-growth equilibrium with different capital income tax rates, at the expense of reducing international wealth-redistributions resulting from tax reforms.

${ }^{8} \mathrm{By}$ focusing on the exogenous-growth case we abstract from long-run growth effects of taxation examined in a large portion of the literature (as in Razin and Yuen (1993), Rebelo (1991), and Milesi-Ferretti and Roubini (1994)). Some authors argue that these effects are not significant (Lucas (1990) and Stokey and Rebelo (1993)). Ignoring endogenous growth also restricts the analysis to the worst-case scenario in which welfare gains and the budgetary impact of tax reforms do not rely on long-run growth effects.

${ }^{9}$ The usual stationary transformations also apply to the subjective discount factor and all endogenous variables, except leisure and labor supply. See King, Plosser, and Rebelo (1988) for details. 
we assume that there are capital-adjustment costs. Sectoral adjustment costs are represented by the function $\Psi\left(K_{t}^{i}, I_{t}^{i}\right)$, for $\mathrm{i}=\mathrm{N}, \mathrm{T}$, to be defined explicitly later.

Households are assumed to have access to a perfectly competitive international capital market where they can buy one-period, discounted bonds that yield a discounted rate $R_{1}$ in units of tradables. Bond purchases are taxed at a rate $\tau_{b}$, which represents a levy on foreign interest income. This tax is set in accordance with the residence principle, which is common practice for international bond transactions among industrial countries. The trend-stationary law of motion for bond accumulation is $\gamma\left(1+\tau_{b}\right) R_{t} B_{t+1}-B_{t}$, which is also the home country's trade balance in units of tradable goods.

Finally, households also derive income from government transfers in units of traded and nontraded goods, $T_{t}^{i}$ for $i=N, T$. These transfers may be positive or negative, and in the latter case they operate as lumpsum taxes. The transfers may be viewed as reflecting in part large welfare programs that represent as much as 20 percent of output in some G-7 countries. Discretionary transfers in addition to those that fund welfare programs may be interpreted as capturing the net effect of government debt, as explained below.

Households also face a constraint on the allocation of time across employment in the traded and nontraded sectors and leisure. Normalizing total time, the constraint is

$$
L_{t}+N_{t}^{N}+N_{t}^{T}=1
$$

Labor is immobile across countries but perfectly mobile across sectors.

Firms

Firms maximize profits subject to costs, taking pre-tax factor prices as given under conditions of perfect competition and constant returns to scale. Thus firms in each sector $i(i=T, N)$ employ inputs according to marginal productivity rules so as to satisfy zero-profit conditions:

$$
F\left(K_{t}^{i} N_{t}^{i}\right)-r_{T}^{i} K_{t}^{i}+\omega_{t}^{i} N_{t}^{i}
$$

Growth-adjusted production functions take the conventional Cobb-Douglas form in each sector $\mathrm{i}=\mathrm{N}, \mathrm{T}$ :

$$
F\left(K_{t}^{i} N_{t}^{i}\right)-\left(K_{t}^{i}\right)\left(N_{t}^{i}\right)^{1-\alpha i}
$$


The Public Sector

The date-t budget constraint on government purchases, $G_{t}^{i}$ for $i=T, N$, is:

$$
G_{t}^{T}+p_{t}^{N} G^{N}+T_{t}^{T}+p_{t}^{N} T^{N}=\tau_{4}\left[\left(r_{t}^{T}-\delta\right) K_{t}^{T}+p_{t}^{N}\left(r_{t}^{N}-\delta\right) K_{t}^{N}\right]+\tau_{-}\left[\omega_{t}^{T} N_{t}^{T}+p_{t}^{N} \omega_{t}^{N} N_{t}^{N}\right]+\tau\left[C_{t}^{T}+p_{t}^{N} C_{t}^{N}\right]+\tau_{b} \gamma R_{t} B_{t, 1}
$$

Thus, total tax revenue derived from factor incomes, consumption, and bond transactions finances government expenditures and transfers. Public debt is not explicitly modelled, but, as in Baxter and King (1993) and Razin and Sadka (1994), we set fiscal policies in terms of distortionary tax rates, a rule for government expenditures, and exogenous, time-invariant levels of transfers funding social programs $\left(\mathrm{T}^{\mathrm{T}}, \mathrm{T}^{\mathrm{N}}\right)$. Thus, the residual endogenous lump-sum transfers that would balance the budget may be viewed as representing the public sector borrowing requirement financed by net public debt issue. The tax-reform experiments examined later rule out the possibility that the long-run public debt position can be enlarged, effectively ruling out permanent changes in long-run lump-sum taxation. During the transition from one tax regime to another, however, residual transfers are allowed in order to meet the government's budget constraint--given fixed tax rates and a path for government expenditures.

Tax rates are assumed to be deterministic and time-invariant, in line with assumptions adopted in recent studies (see Cooley and Hansen (1992) and Lucas (1990)). Deterministic taxes isolate the analysis of once-and-for-all tax reforms from the effects of policy uncertainty and credibility, and time-invariant taxes focus attention on tax reforms less sophisticated than those suggested by dynamic Ramsey optimal taxation problems. The solutions of these problems (as noted in Lucas (1990) and Chari, Christiano and Kehoe (1994)) typically require time-variant tax rates, with minimal or zero labor income tax rates and high capital income tax rates in the first periods of a tax reform and the opposite in the long-run. However, these strategies face problems of time consistency and are questioned in some public finance work (Feldstein (1976)) for being impractical and politically inviable. Cooley and Hansen (1992) show, in addition, that extra gains resulting from two-step relative to one-step reforms are very small.

The intertemporal path of government purchases is set according to the relative or absolute rules mentioned earlier. Under the relative rule, which follows Lucas (1990) and is in line with common practice 
$-10-$

in policy-making circles, the policy is to maintain constant government expenditures relative to the size of the economy. To facilitate the next section's analysis of social optimum policies in the presence of the depreciation tax allowance, the relative rule is expressed as a share of net domestic product (NDP). Under the absolute rule, which reflects the assumption in Cooley and Hansen (1992), the fiscal authority keeps the level of real government expenditures constant.

\section{Market Clearing}

The market-clearing conditions in goods markets and in the bonds market are:

$$
\begin{aligned}
& F\left(K_{t}^{T}, N_{t}^{T}\right)+F\left(K_{t}^{T_{*}, N_{t}^{T}}\right)=C_{t}^{T}+C_{t}^{T_{*}}+I_{t}^{T}+I_{t}^{T_{*}}+\Psi\left(K_{t}^{T}, T_{t}^{T_{t}}\right)+\Psi\left(K_{t}^{T_{*}}, I_{t}^{T_{*}}\right)+G_{t}^{T}+G_{t}^{T_{*}} \\
& F\left(K_{t}^{N}, N_{t}^{N}\right)=C_{t}^{N}+I_{t}^{N}+\Psi\left(K_{t}^{N}, I_{t}^{N}\right)+G_{t}^{N} \\
& F\left(K_{t}^{N_{*}}, N_{t}^{N_{*}}\right)=C_{t}^{N_{*}}+I_{t}^{N_{*}}+\Psi\left(K_{t}^{N_{*}}, I_{t}^{N_{*}}\right)+G_{t}^{N_{*}} \\
& B_{i}+B_{i}^{\prime}=0
\end{aligned}
$$

\subsection{Competitive Equilibrium and Numerical Solution}

An intertemporal equilibrium for the world economy is given by sequences of prices and allocations:

$$
\begin{aligned}
& {\left[p_{1}^{N}, p_{1}^{N \cdot}, r_{1}^{T}, r_{1}^{T}, r_{1}^{N}, r_{1}^{N}, R_{f} w_{1}^{T}, w_{1}^{N}, w_{1}^{T_{*}^{*}}, w_{1}^{N_{*}^{*}}\right]_{t=0}^{\infty}} \\
& {\left[K_{t, 1}^{N}, K_{t, 1}^{N \cdot}, K_{t, 1}^{T}, K_{t, 1}^{T \cdot}, B_{t, 1}, B_{t, 1}^{*}, N_{t}^{N}, N_{t}^{T}, N_{t}^{N *}, N_{t}^{T \cdot}, C_{t}^{N}, C_{t}^{T}, C_{t}^{N \cdot}, C_{t}^{T \cdot}, L_{p} L_{i}\right]_{t=0}^{\infty}}
\end{aligned}
$$

that satisfy the first-order conditions of the optimization problems faced by households and firms in the two countries, the period-t budget constraints of households and governments in the two countries, and the market-clearing conditions--given date-0 capital stocks and bond positions. Equilibrium also requires intertemporal solvency by households and governments. Thus, the present discounted value of the trade balance must be equal to the initial stock of net foreign bonds, and the present value of government expenditures must equal that of revenues.

We compute a numerical solution for this competitive equilibrium using a variant of the linear approximation method developed by King, Plosser and Rebelo (1988), altered to address the indeterminacy of the stationary equilibrium of the tax-distorted, two-country model with trade in bonds. This modification is necessary because the conventional KPR method solves for equilibrium dynamics around steady-state allocations, which in the model cannot be solved for in closed-form because long-run foreign asset positions, 
$-11-$

and hence long-run consumption allocations, are indeterminate. In models without tax distortions (as in Backus et al. (1992) or Stockman and Tesar (1995)), the equivalence between the competitive equilibrium and the social optimum can be exploited to determine steady-state consumption allocations for a given set of welfare weights in a world social planner's problem. With tax distortions this equivalence does not hold, and the competitive equilibrium must be solved directly.

The model examined here is similar to the two-country model of Lipton et al. (1983), in which steady-state foreign asset and consumption allocations are solutions of a two-point boundary problem that requires the numerical analysis of the model's dynamics. Given initial conditions, steady-state allocations are solved by numerical simulation using single or multiple shooting. Direct, one-shot application of the KPR method is inappropriate because it characterizes dynamics near steady-state bond positions that are unlikely to be consistent with current account dynamics starting from the pre-tax-reform equilibrium. While this inconsistency may not affect applications of the KPR method to international RBC models, which focus on high-frequency behavior, it must be addressed for long-run policy analysis.

Our approach here is to solve for competitive equilibrium allocations using the KPR method as an iterative routine within a shooting algorithm. We take an initial guess of the long-run foreign asset positions to which each country converges after a tax reform and linearize around it to build the KPR algorithm. Then we simulate the transitional dynamics for 2500 periods given the model's pre-reform equilibrium state variables as initial conditions. The simulations produce a path of current-account dynamics that converges to long-run foreign asset positions. If these differ from the initial guess, the new results are adopted as the new guess and the process is repeated. Convergence is usually obtained in 4 or 5 iterations. By proceeding in this manner, it is ensured that the paths of foreign asset accumulation satisfy intertemporal solvency, and that post-reform steady-state foreign asset positions are consistent with current-account dynamics starting from the initial conditions corresponding to the pre-reform equilibrium.

Another important feature of the model's solution is the fact that the assumptions of exogenous world balanced growth under perfect capital mobility and residence-based taxation constrain the set of tax policies on bond transactions compatible with a competitive equilibrium. Specifically, bond purchases must be taxed 
at the same rate in both countries. This result follows from the Euler conditions equating intertemporal marginal rates of substitution of households in each country with the post-tax rate of return on world bonds ${ }^{10}$. Since balanced growth restricts consumption to grow at the same steady-state rate in both countries, and since both countries face the same pre-tax rate of return on bonds, the equilibrium is viable only if the tax on bonds is the same in each country. This is in line with the view in Frenkel, Razin and Sadka (1993) that residence-based taxation requires some degree of global tax coordination. Taxes on capital income are not constrained in the same manner because home (foreign) households cannot hold foreign (domestic) capital, and hence although arbitrage equalizes post-tax rates of return across countries, pre-tax rates vary to offset differences in capital income taxes."

\subsection{The World Pre-Tax-Reform Equilibrium}

The model is calibrated to reflect broad features of the data for large industrial countries obtained from OECD publications (Quarterly National Income Accounts, National Accounts, and Revenue Statistics.). The home country (Country A) is calibrated to U.S. data, and the foreign country (Country B) is set to reflect an aggregate of the four largest European economies (France, Germany, Italy and the United Kingdom ). European aggregates of the GDP shares used for calibration are created with simple arithmetic averages.

The model is parameterized following standard procedure in RBC analysis. Preference and technology parameters are assumed to be identical in the two countries. The coefficient of relative risk aversion $\sigma$ is set equal to 2 , the private subjective discount rate $B$ is 0.998 , and the quarterly rate of laboraugmenting technical progress is 1.007 (consistent with an average annual GDP growth rate of 3 percent). These parameters imply a steady-state real interest rate of 7 percent per annum, in line with the long-run average yield of risky assets, and they also determine the growth-adjusted discount factor $\beta$ that enters the households' lifetime utility function $\left(\beta=B \gamma^{1-\alpha}=0.99\right)$. The elasticity of substitution between traded and

\footnotetext{
${ }^{10}$ The model's optimality conditions are conventional expressions and hence are omitted to save space. They are available from the authors on request.

"Trade in equity would imply that taxes on capital income must also be coordinated to ensure that pre-tax rates of return on capital are equalized. Under world balanced growth and residence-based taxation, capital income taxes would need to be identical everywhere. A restriction coordinating capital taxes would apply even if countries grew at different rates--sustainable differences in capital taxes are determined by the differences in growth rates.
} 
nontraded goods is set equal to $0.44(\mu=1.273)$, as estimated by Stockman and Tesar (1995). ${ }^{12}$ The elasticities of substitution in leisure $\left(\mathrm{a}\right.$ and $\left.\mathrm{a}^{*}\right)$ are set to 2.8 following the common practice in RBC models of setting this parameter to produce steady-state labor supply allocations equal to 20 percent of total time. However, as Lucas (1990) notes, estimates of this parameter are subject of debate and have important implications for quantitative welfare analysis. The labor shares in traded- and nontraded-sectors are set to 0.61 and 0.56 respectively, reflecting estimates by Stockman and Tesar (1995). The quarterly depreciation

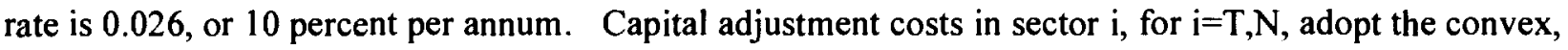
quadratic form:

$$
\Psi\left(K_{t}^{\prime}, I_{t}\right)=\frac{\eta}{2}\left(\frac{I_{t}{ }^{\prime}}{K_{t}^{i}}-b^{\prime}\right)^{2} K_{t}^{i}
$$

where $b^{i}$ is set equal to the steady-state ratio of investment to the capital stock, so that adjustment costs are zero in steady-state. $\eta$ is set equal to 0.45 , which in business-cycle variants of the model, driven by productivity shocks, results in investment standard deviations similar to those observed in the data.

In addition to preference and technology parameters, the model's calibration requires fiscal policy parameters. These parameters need to be measured accurately for the model's quantitative predictions to be useful input for policy discussions. Moreover, given the high degree of symmetry in preferences and technology, and the absence of asymmetric exogenous shocks, fiscal policy asymmetries are the model's main source of gains from trade explaining the pattern of international borrowing and lending.

Measuring the level and output shares of government expenditures and transfers using existing data is straightforward. As shown in Table 1, government expenditures and transfers averaged 19 percent and 14 percent of GDP respectively in the United States over the period 1968-1991, compared to larger shares of 21 and 24 percent of GDP in Europe. Obtaining appropriate estimates of effective tax rates on factor incomes and consumption is a far more complex exercise. The myriad of credits, deductions, and exemptions that national tax codes allow, and the progressivity and nonlinearity of tax schedules, make it

\footnotetext{
${ }^{12}$ Estimates in Mendoza (1995) and Ostry and Reinhart (1992) suggest that higher values may also be consistent with the data.
} 
difficult to estimate effective tax rates useful for macroeconomic modelling. We examined these issues, and the manner in which they have been dealt with in the literature in Mendoza, Razin, and Tesar (1994). There we constructed estimates of G-7 time-series of effective tax rates on labor income, capital income, and consumption that are used to pin down the tax rates for the U.S. and Europe in the pre-tax-reform equilibrium of the model. The time-series averages of the consumption (capital income) tax rates are 5.8 (43) percent for the United States and 16 (32.8) percent for the G-4 of Europe. In light of the marked upward trend of labor income tax rates in all G-7 countries, reflecting the secular rise in social security taxes, we set labor tax rates using the end-of-sample point estimates for 1988, which imply labor tax rates of 28.5 percent for the United States and 39 percent for Europe. Despite the ongoing debate on tax rate estimates, this configuration captures a widely-accepted view of the main differences in tax policy between Europe and the United States--compared to European countries, the United States taxes relatively less consumption and labor income and more capital income. The tax on bond purchases is set to zero in the benchmark version of the model, and we examine alternative versions consistent with uniform residence-based taxation of domestic capital and foreign interest income in the United States. ${ }^{13}$

The steady-state, balanced-growth equilibrium allocations of the model are solved for given benchmark parameters describing preferences, technology, and fiscal policies. Although deriving the system of steady-state equilibrium conditions is straightforward, computing steady-state allocations is complicated by the indeterminacy of foreign asset positions and consumption allocations discussed earlier. In the initial benchmark, the model is calibrated to mimic the 1970-1992 quarterly average of the GPD share of net foreign asset holdings in the United States ( 2.8 percent), computed using data from the OECD Analytical Database. The steady-state after a tax reform is determined by simulating the model using the shooting algorithm to find the new long-run net foreign asset position to which each country converges.

The steady-state system produces sectoral allocations which are aggregated into shares of total GDP. The aggregate output shares in the pre-tax-reform steady state are compared with actual GDP shares in Table

\footnotetext{
${ }^{13}$ This implies that $\tau_{b}$ is set so that domestic capital income and interest income derived from foreign bonds are taxed uniformly at the 43 percent rate in the home country. This in turn implies that the world's real interest rate is equal to the home country's pre-tax net marginal product of capital.
} 
1 so as to assess the consistency of the model's initial equilibrium. Table 1 shows the 1968-1991 average GDP shares of consumption, investment, net exports, tax revenue, and government transfers for the United States and the European G-4. In the United States, private consumption expenditures account for roughly 65 percent of output and private investment is about 16 percent. In the European countries, consumption accounts for a smaller share of GDP than in the United States, while the investment share is roughly comparable. The United States report a small trade deficit of 1 percent of GDP while the European countries show a small surplus. Tax revenues, measured as total tax receipts from federal, state, provincial and local governments, are 36 percent of GDP in Europe, compared to a smaller U.S. share of 28 percent of GDP. ${ }^{14}$ The magnitude and cross-country ranking of GDP shares in the data are roughly in line with the model, except that the shares of consumption are lower and those of investment are higher relative to the data. These shares are sensitive to labor income shares on which there is mix evidence--a value of 0.76 as in Lucas (1990) results in consumption and investment shares very similar to those observed in the data.

\section{Costs of Distortionary Taxes and Effects of Replacing Income Taxes with Consumption Taxes}

This section begins with a characterization of social optimum policies and an assessment of the welfare gains that would result from eliminating all distortionary taxes as currently set in the United States and Europe. We then examine a more realistic tax reform in which factor income taxes are set as dictated by the social optimum, but distortionary consumption taxes are used to balance the budget so as to finance predetermined targets of current expenditures and transfers. The simulation analysis compares closed- with open-economy results, to isolate the transmission mechanisms at work in a global economy, and considers both the case in which the tax reforms are implemented unilaterally and the case in which all countries introduce simultaneous tax reforms. These experiments also resemble experiments conducted in the closedeconomy studies of Lucas (1990) and Cooley and Hansen (1992).

Social Optimum Policies

Given the structure of the model, it is straightforward to characterize tax policies that, if chosen

\footnotetext{
${ }^{14}$ The large differences between these measures of the overall tax burden and the effective tax rates on factor incomes and consumption computed in Mendoza, Razin and Tesar (1994) suggest that using the share of tax revenue in GDP as a measure of effective tax rates is a poor approximation in equilibrium analysis.
} 
without restricting the choice of taxes, would reproduce the Pareto-optimal outcome determined by a social planner. The planner maximizes the weighted sum of country-specific lifetime utilities for given welfare weights $\phi$ and $1-\phi$ :

$$
\phi\left[\sum_{t=0}^{\infty} \beta^{t} U\left(C_{t}^{T}, C_{t}^{N}, L_{t}\right)\right]+(1-\phi)\left[\sum_{t=0}^{-} \beta^{t} U\left(C_{t}^{T *}, C_{t}^{N *}, L_{t}^{*}\right)\right]
$$

Subject to the resource constraints (8)-(10). This additive world welfare function is widely used in studies of international policy coordination (see Chari and Kehoe (1990) and Canzoneri and Henderson (1991).

The solution to the planner's problem depends on the rule dictating government expenditures. Under the absolute rule, it is well-known that zero tax rates on factor incomes and consumption, and full use of lump-sum taxation, result in a competitive equilibrium identical to the social optimum. ${ }^{\text {is }}$ In contrast, if governments follow the relative rule, the social optimum would be recreated by the competitive equilibrium only if each country sets time-invariant capital and labor income tax rates equal to the share of NDP absorbed by each government and consumption tax rates are set to zero. ${ }^{16}$ Note, however, that this policy still requires lump-sum taxation to cover any revenue shortfall needed to finance exogenous transfers representing welfare programs.

Table 2 reports the results of implementing optimal policies that replace all distortionary taxes with social optimum taxes in the two countries, starting from the initial pre-tax-reform equilibrium determined by current fiscal policies. The table lists balanced-growth, steady-state levels of the major macroeconomic aggregates in the pre-tax-reform equilibrium and the corresponding percentage changes, or basis point changes for variables initially measured in percent, under the social optimum policies. ${ }^{17}$ The percentage gain

\footnotetext{
${ }^{15}$ Without loss of generality we set government purchases to zero under the absolute rule, which reduces to the case in which tax revenue is rebated as a lump-sum transfer, so that taxes cause only relative price distortions.

${ }^{16}$ See the Appendix for a formal proof. We thank Robert King for calling our attention to this result.

${ }^{17}$ The solution of the competitive equilibrium transition to social optimum taxes provides a means for determining the appropriate value of $\phi$ in the planner's problem. It is straightforward to show that both the competitive equilibrium and the planner's solution share the feature that the ratio of home to foreign marginal utilities of tradables is time-invariant, and hence can be determined using the corresponding steady-state ratio to which the competitive equilibrium converges when current taxes are replaced with social optimum taxes. In the planner's problem the ratio of marginal utilities of tradables across countries is equal to $\phi /(1-\phi) . \phi=0.51$ for the open economy under the relative $G$ rule and zero tax on bonds.
} 
in social welfare includes the cost of the transitional dynamics incurred in the process of expanding the capital stock from the tax-distorted equilibrium to the Pareto-efficient equilibrium. Welfare gains are measured following the standard method introduced in Lucas (1987), by computing an across-the-board percentage increase in consumption of traded and nontraded goods at all dates that leaves the consumer indifferent, in terms of lifetime utility, between the welfare obtained by remaining in the steady-state pre-taxreform equilibrium and the welfare obtained by shifting to social optimum taxes (considering the transitional dynamics of consumption and leisure).

Table 2 shows that, under the relative G rule, the welfare gain for the U.S. viewed as a closed economy is 2.49 percent, compared to 2.44 percent in the open economy without a tax on bonds, and 2.33 in the open economy with home-residence-based bond taxes. If $\mathrm{G}$ follows the absolute rule, the welfare gain in the closed economy is 12.87 percent, and in the two open economies the gains are 12.97 and 12.93 percent. ${ }^{18}$ The much smaller welfare gains under the relative rule reflect the fact that government purchases grow in proportion to the rest of the economy, and hence households suffer from the adverse wealth effect of larger unproductive government expenditures. Social optimum taxes under the relative rule also maintain taxes on factor incomes that represent large distortions from the perspective of the social optimum under the absolute rule. Home welfare gains for open economies with taxes on bonds are slightly smaller than for economies with zero taxes on bonds. This results from an international externality operating through a longrun income-redistribution effect that is discussed in detail later.

In the context of Pareto-efficient equilibria under the absolute $G$ rule, the LeChatelier's principle applies, and hence welfare gains for open economies must exceed those of the closed economy, since the allocations of the closed economy remain feasible and there are no tax distortions. Later we find that the same does not apply when comparing tax-distorted equilibria between closed and open economies. Moreover, if $\mathrm{G}$ follows the relative rule, the gain of an open economy may not exceed that of a closed economy because in the former the capital stock, and hence NDP and government expenditures, adjust faster

\footnotetext{
${ }^{18}$ These results are in line with the closed-economy analysis of Cooley and Hansen (1992). They report that the gain (net of transitional dynamics) of replacing a capital tax of 50 percent and a labor tax of 23 percent with lump-sum taxation, given a fixed level of government expenditures, is 13.3 percent.
} 
$-18-$

to their new, higher long-run equilibria. ${ }^{19}$ The difference in welfare gains of moving to a social optimum are nevertheless minimal.

The extra $1 / 10$ of a percentage point in welfare that open economies under the absolute $G$ rule gain relative to the closed economy measures the gains derived from international bond trading. These gains have two components: (a) a smoothing component, which reflects a country's use of international markets to borrow during the transition, thus avoiding as sharp a fall in consumption and utility as in a closed economy, and (b) a long-run income-redistribution effect, resulting from net foreign interest income, or payments, on the steady-state bond positions to which each country converges after the tax reform. Because of the symmetry of preferences and technology, and because social optimum taxes are implemented in the two countries simultaneously, these effects are weaker in Table 2 than they will be later when we examine tax reforms limited to distortionary taxes.

\section{Unilateral Substitution of Direct Taxes for Indirect Taxes}

Since in practice full lump-sum taxation is not feasible, the analysis of social optimum policies is interesting only because it provides estimates of the overall costs of distortionary taxes, and because it helps isolate the transmission mechanisms particular to the open economy. We now consider a more realistic case in which discretionary lump-sum taxation is ruled-out. In particular, tax policy is set within the class of time-invariant tax rates, given a government expenditure rule and subject to a long-run constraint on net transfers to households. As with the $\mathrm{G}$ rules, the constraint on transfers can be absolute or relative. The steady-state government budget constraint implies then that of the three distortionary taxes $\left(\tau_{k}, \tau_{n}, \tau_{c}\right)$ only two can be set freely and the third must be set so that tax revenue matches the exogenously-given targets of transfers and expenditures. Because taxes are time invariant, transfers finance revenue shortfalls, or rebate surpluses, along the transitional path. Following the discussion in Section 2, these transitional dynamics of transfers can be interpreted as public debt dynamics that converge to a pre-determined long-run target. Thus,

${ }^{19}$ In this case, open economies experience faster transitional growth in government absorption compared to a closed economy because external borrowing allows faster adjustment of the capital stock and output to the taxreformed steady-state levels. If adjustment costs were zero, NDP and G, would rise to their new higher long-run levels one period after the reform starts, reflecting the instantaneous adjustment of capital financed by foreign borrowing, compared to a more gradual adjustment in a closed economy. 
we refer to this constrained tax-choice setting as a long-run public debt constraint.

As noted earlier, under the absolute $G$ rule the social optimum requires zero distortionary tax rates and full use of lump-sum taxation, and thus the social optimum cannot be recreated once we impose an absolute long-run public debt constraint, unless by chance it matches the desired amount of lump-sum transfers. Interestingly, however, under the relative $\mathrm{G}$ rule and a relative long-run public debt constraint, the constant-elasticity functions used to describe preferences and technology imply that there is a mix of time-invariant direct and indirect tax rates that can recreate the social optimum (see the Appendix). ${ }^{20}$ This optimal tax strategy requires that $\tau_{k}$ be set equal to the share of G in NDP, and that $\tau_{n}$ and $\tau_{c}$ be set so that (a) there is a wedge between pre-tax and post-tax real wages such that $\left(1-\tau^{n}\right) /\left(1+\tau_{c}\right)=1-G / N D P$, and (b) the steady-state government budget constraint is satisfied given G/NDP, $\tau_{\mathrm{k}}$, and the target ratio of transfers to GDP. Unfortunately, under reasonable parameter specifications, this implies very large labor subsidies and very large consumption taxes--given the benchmark model's parameters, the optimal taxes are $\tau_{\mathrm{n}}=-81$ percent and $\tau_{c}=135$ percent. Thus, we conclude that although this is an interesting optimal taxation result, which lends support to the use of time-invariant tax rates in our model, it is as unrealistic as lump-sum taxation.

Instead of studying first-best optimal tax strategies or solutions to dynamic Ramsey optimal taxation problems, the experiments that follow focus on tax reforms that represent partial welfare improvements, in the spirit of Feldstein's (1976) reforms that constitute "small steps in the right direction." In particular, we conduct experiments in which factor income taxes are reduced to the levels implied by social optimum policies (i.e. zero under the absolute $G$ rule and the share of G in NDP under the relative rule), but impose the long-run public debt constraint so that $\tau_{\mathrm{c}}$ adjusts to balance the budget. ${ }^{21}$ The need to find a $\tau_{\mathrm{c}}$ that finances a target for transfers in the tax-reformed steady-state implies that the numerical solution must incorporate an additional iterative routine. Starting from an initial guess of unchanged consumption taxes, we examine whether the long-run public debt constraint holds every time the shooting algorithm in foreign

\footnotetext{
${ }^{20} \mathrm{This}$ optimal policy is also time-consistent, since it recreates the first-best outcome. This result is in line with the example for a constant $G$ rule in the barter economy without capital examined by Lucas and Stokey (1983).

${ }^{21}$ Theses tax policies are interesting because they are roughly in line with the savings-oriented tax reform proposals of Sen. William Archer and Sen. Pete Domenici in the U.S. Congress.
} 
bonds is completed. If the constraint does not hold, a new guess for $\tau_{c}$ is obtained so as to satisfy the constraint under the latest solution for the steady-state system. The shooting algorithm is then executed again until there is convergence both in net foreign asset positions and in consumption tax rates. This additional routine normally converges within 5 iterations. These iterations on consumption taxes can be viewed as a shooting algorithm on net government borrowing that determines a dynamic path of public debt issue consistent with an unchanged steady-state level, or output ratio, of net public debt (see Appendix).

Table 3 summarizes the results of a unilateral income-for-consumption tax reform. Welfare gains in this case are significantly smaller than those reported in Table 2, which reflects mainly the large magnitude of the distortions due to suboptimal consumption taxes on the leisure-consumption choice. ${ }^{22}$ If social optimum taxes were feasible, home-country leisure would fall by 3.2 percentage points from the 80 percent level in the pre-tax reform equilibrium of either closed or open economies (see Table 2), and consumption would rise by nearly 20 percent. In contrast, since with an income-for-consumption tax reform $\tau_{\mathrm{c}}$ rises from 5.8 to 20.5-32 percent (depending on whether we focus on closed or open economies and whether we consider the tax on bonds or not), the effect of the lower labor income tax on leisure is virtually neutralized, as it remains near 80 percent, and the increase in consumption is only in the range $2.2-4$ percent. Still, the welfare gains of this unilateral reform for the home country are significant, particularly if bond purchases are tax free--near 1 percent under the relative $G$ rule and about 9 percent under the absolute $G$ rule.

The welfare gains obtained in the closed economy are consistent with those computed by Lucas (1990) and Cooley and Hansen (1992), although the figures are not identical due to differences in the structure of preferences and technology, the levels and types of taxes considered, and the assumed government expenditure rule. Using an alternative solution method, Cooley and Hansen (1992) found that the welfare cost of tax distortions that remain after $\tau_{k}$ is replaced by $\tau_{c}$, holding $\tau_{n}$ fixed at 23 percent and under the absolute $\mathrm{G}$ rule, is 10.5 percent--in terms of an increase in lifetime consumption needed for the tax-

\footnotetext{
${ }^{22}$ As Lucas (1990) shows, the magnitude of these distortions is highly dependent on the parameter structure, particularly on the leisure elasticity. A value of $a=2.8$ as implied by the restriction to produce a 20 percent steady-state labor time allocation in the model is significantly larger than the value used by Lucas (0.6).
} 
reformed economy to produce the same utility as the social optimum with lump-sum taxes. ${ }^{23}$ The corresponding welfare cost measure that compares pre- and post-tax-reform steady-states is 6.6 percent, which indicates that the welfare cost rises by a factor of 1.6 on account of transitional dynamics. In our model, a similar experiment yields a welfare gain net of transitional dynamics of 4.5 percent relative to the pre-tax-reform equilibrium. The corresponding welfare gain excluding transitional dynamics is about 2.3 times larger, suggesting that transitional dynamics under our parameter specification are somewhat more costly than in the Cooley-Hansen model. Lucas (1990) discusses alternative approximation methods to compute transitional dynamics and concludes that the welfare gain of replacing $\tau_{k}$ with $\tau_{n}$, under the relative $\mathrm{G}$ rule and using a measure of $\tau_{\mathrm{n}}$ that includes indirect taxes, is in the range $0.75-1.25$ percent. In our model, the welfare gain net of transitional dynamics of an experiment where both factor income taxes are set to zero and replaced with a large consumption tax is 1.6 percent.

Beyond the effects of the distortion of the consumption tax on the leisure-consumption margin, which is a feature of both closed and open economies, there are two important findings particular to the open economy. First, with the suboptimal tax reform, an open economy can obtain noticeably smaller welfare gains than a closed economy. With tax-free bond purchases the differences in welfare across experiments are negligible. However, with the home-residence-based tax on bonds and under the relative $G$ rule, the home country welfare gain is 0.18 percent v. 1.06 percent in a closed economy. This result follows from the fact that in this case the home country in the open economy requires a larger increase in $\tau_{c}$ to meet the longrun public debt constraint than a closed economy. This in turn follows from (a) the smaller base of the home consumption tax, since steady-state consumption in the open economy rises 2.2 percent, compared to 3.9 percent in the closed economy, and (b) the loss of revenue from the tax on bonds as the home country's borrowing decisions during the transition lead to a decline in net foreign assets from near 0 to -0.8 . The long-run income redistribution effect resulting from this worsening capital account, reflected in the interest payments on external debt, also explains why consumption grows less in the open economy. To service its

\footnotetext{
${ }^{23}$ Their method is based on linear approximations near the steady-state and simultaneous solution of the non-linear Euler equations to trace the dynamics off the steady state.
} 
foreign debt, the home country must sustain a long-run trade surplus about 1.5 percent of GDP larger than under current fiscal policies.

The second important finding is that foreign welfare is affected by a unilateral home tax reform--by as much as a loss of 0.8 percent under the absolute $\mathrm{G}$ rule--and that the magnitude and direction of this international externality depends on the tax on bond purchases. The reduction in the home capital tax rate triggers large capital outflows away from the foreign country and results in declines in foreign output, consumption, and capital stock. The transition to a lower capital stock abroad moderates the foreign welfare loss, for it implies a period of temporarily high consumption and leisure relative to new, lower steady-state levels. Under the relative $\mathrm{G}$ rule, foreign welfare falls by 0.16 percent if bond purchases are tax-free, but if bond purchases are taxed according to the pure residence principle at home, foreign welfare rises by 0.6 percent. ${ }^{24}$ In the latter case foreign welfare rises because the income-redistribution effect, implied by a larger long-run debt position in the home country and a higher world real interest rate, more than offset the adverse effect of the contraction in foreign GDP. In the case that government follows the absolute G rule, the results with and without bond taxes are not very different because in the two cases the reformed level of the bond tax rate is zero.

To illustrate further the role of the tax on bonds as a means for distributing the gains of tax reforms across countries, consider two alternative scenarios for $\tau_{b}$ under the relative $G$ rule. First set $\tau_{b}$ according to the pure residence principle in the foreign country, so that the pre-tax rate of return on bonds equals the foreign net marginal product of capital (i.e. $\tau_{b}=0.82$ ). Home and foreign welfare gains are now -0.37 and 0.96 percent respectively. Second, set $\tau_{\mathrm{b}}$ arbitrarily to provide a subsidy of $1 / 10$ of a percent. The home country's welfare gain now rises to 1.1 percent, while the foreign country's gain falls to -0.31 percent. An analysis of the transitional dynamics of these different experiments does not show any noticeable differences in the intertemporal adjustment of macroeconomic aggregates. The major differences are in each country's long-run net foreign asset position and in the level of the long-run equilibrium world real interest rate. A

\footnotetext{
${ }^{24}$ The foreign government is forced to reduce its purchases as foreign NDP falls, thus lessening the adverse effect of government absorption on foreign welfare.
} 
lower (higher) tax on bonds results in a larger (smaller) long-run debt position for the home country and a lower (higher) long-run equilibrium real interest rate, hence resulting in a larger (smaller) welfare gain. Thus, the tax on bonds effects a cross-country reallocation of the welfare gains mainly through the incomeredistribution effect.

The transmission mechanisms at work in open economies during tax reforms are illustrated in more detail in Figures 1-8, which plot the transitional dynamics of macroeconomic aggregates. The charts plot dynamics starting from the steady-state levels of the pre-tax-reform equilibrium for the closed economy and the two countries in the open economy for the experiment assuming no tax on bonds and the relative $G$ rule. The model produces simulations for 2500 quarters, although the charts only plot the first 100 quarters.

Figure 1 plots the dynamics of the aggregate capital stock in units of the traded good. ${ }^{25}$ The home country's capital stock is always higher when the economy is open relative to when it is closed. On impact, the difference is due in part to a real appreciation that raises the valuation of the non-traded sector capital stock. During the rest of the transition, and in the long-run, both closed and open economies have the same capital-output ratios but the levels of output and capital are higher for the open economy because of the higher level of labor supplied in the open economy (see Figure 3). Comparing the home and foreign countries, it is clear that a unilateral tax reform under perfect capital mobility triggers a large outflow of capital from the foreign country into the home country.

The key to understanding the welfare implications of the tax reform is in the transitional dynamics of the CES composite good, leisure, and momentary utility (Figures 2-4). There are three important features of these dynamics:

(1) In the initial stages of the transition for either a closed or an open economy, consumption and utility are

\footnotetext{
${ }^{23}$ Since home-country pre-reform $\mathrm{K}$ is 28 percent smaller than after the reform, one may doubt the accuracy of linear approximations. We explored this issue by constructing a closed-economy model that matches Cooley and Hansen (1992), except that money is not considered. We obtained similar welfare assessments and transition paths. We also examined the robustness of open-economy solutions by showing that social optimum policies are not dominated by other tax policies. With social optimum taxes as initial conditions, no other tax system produces higher welfare. If the social optimum is the target to reach from distorted equilibria, small subsidies may dominate social optima for very large initial distortions due to inaccuracies of the KPR method in capturing the initial stages of transition. Thus, in the worst-case scenario we are underestimating actual welfare gains.
} 
lower than they were in the pre-tax-reform equilibrium. For the tax reform to be welfare-improving, this short-lived recession must not outweigh the latter expansion and the ultimately permanent increase in utility resulting from the tax reform.

(2) Agents with access to world markets try to smooth the effects of the tax reform, and thus, consumption, leisure, and momentary utility do not fall as much in the short-run as they do in a closed economy--although in the long-run home households in the open economy end up consuming less of the two goods and reach a lower level of momentary utility (see Figures 2,3 and 4). The lower long-run utility in the open economy reflects in part the income-redistribution that takes place as the home economy maintains a long-run trade surplus to service its increased foreign debt (see Figure 8). The net of-transition welfare gain may be larger or smaller in the open economy than in the closed economy depending on how large the gains of smoothing are, compared to the extra distortions that result from the higher home consumption tax and the faster adjustment of home government expenditures in the open economy (see Figure 5 and Table 3).

(3) Home and foreign countries share the consumption gains of a unilateral tax reform--CES consumption is almost equalized across countries from the moment the tax reform is enacted--but there is a large asymmetry in the dynamics of leisure, which results in the 0.16 percent welfare loss for the foreign country reported in Table 3. While home leisure rises very slightly during the transition and eventually falls by a small amount below the original steady-state, foreign leisure falls sharply initially and ends up only slightly higher than in the pre-reform equilibrium (Figure 3) ${ }^{26}$ The initial sharp fall in foreign leisure reflects an 11 percent increase in labor supplied to the traded sector, which is needed to supply extra traded goods demanded by the home country during the transition--at the same time that the capital stock in the foreign traded sector is being depleted. The adverse effect of these dynamics on foreign welfare is partially offset by the declining path of foreign government expenditures as foreign NDP falls (Figure 5).

The international externalities affecting real aggregates discussed above are reflected in the relative price dynamics illustrated in Figures 6 and 7. Figure 6 plots the real interest rate paid on world bonds in units of tradables (i.e. the intertemporal relative price of tradables consumption) and the home and foreign

\footnotetext{
${ }^{26} \mathrm{Also}$, the dynamics of home leisure in the open economy are the opposite to those in the closed economy.
} 
domestic, consumer-based real interest rates (i.e. the intertemporal relative price of the CES composite) ${ }^{27}$ Figure 7 plots the real exchange rates (i.e. the relative price of nontraded goods in terms of traded goods). Note that, with the exception of the home-country real exchange rate, which falls slightly in the long-run as capital-output ratios rise in the home country, all relative price effects operating through the real interest rate and the real exchange rate are at work only during the transition. In the long-run all interest rates (Figure 6) and the foreign real exchange rate (Figure 7) return to pre-reform benchmarks. In the first-quarter after the reform is enacted, however, the domestic real exchange rate rises by 7 percent and the foreign real exchange rate falls by 6 percent. The expectation that both real exchange rates will fall as they move towards the steady-state induces an increase in the home interest rate and a fall in the foreign interest rate that results in a real interest differential as large as $1 / 3$ of a percentage point on impact after the tax reform is introduced. The domestic interest rates also reflect a small short-run increase in the world real interest rate from 1.706 to 1.71 percent. The fluctuations in interest rates are small in general, but they are sufficient to induce the large fluctuations in real allocations illustrated in Figures 1-5.

Figure 8 plots the transitional dynamics of net international bond holdings and the trade balanceGDP ratio in the foreign economy. The foreign country's net foreign asset position rises from close to zero to about 0.8 in units of traded goods, which reflects the pattern of intertemporal lending by which the foreign country finances part of the expansion of the home country's capital stock. The increasing path of net bond holdings abroad thus acts as the vehicle for the outflow of capital into the domestic economy discussed earlier. The sharp rise in foreign net exports on impact after the reform is introduced, from near balance to a surplus of more than 6 percent of GDP, is an indicator of the amount of financing that the foreign country is providing to home households. In the long-run, the present discounted value of net exports matches initial bond holdings, and hence the foreign country's trade balance eventually settles to a deficit of about 1.2 percent of GDP, which reflects the home-country's servicing of a higher long-run debt position. The

\footnotetext{
${ }^{27}$ These interest rates are the returns that a one-period debt contract in terms of the CES composite pay in each country. As in Frenkel and Razin (1987), these returns reflect the intertemporal marginal rates of substitution in consumption in terms of the CES good in the first stage of a two-stage consumer optimization problem. In equilibrium the consumer-based real interest rate is $\mathrm{p}^{\mathrm{N}}{ }_{t+1} / \mathrm{p}^{\mathrm{N}} \mathrm{R}_{\mathrm{t}}$ (see Mendoza (1995) for details).
} 
temporary surge in the foreign trade surplus reflects the smoothing effect of the tax reform, while the convergence towards a small trade deficit reflects the long-run income-redistribution effect.

Summing up, these results suggest that international borrowing and lending have significant implications for the effects of tax reforms. While the gains of a tax reform reducing factor income taxes and raising the consumption tax are substantial, the pattern of net borrowing during the transition and the changes in long-run debt introduce significant distortions. As a result, the welfare gains of the reform may be smaller in an open than in a closed economy, and the gains of a unilateral home tax reform may be partially at the expense of, or partially transferred to, the foreign country. Which way this externality operates depends on the pattern of intertemporal borrowing and on tax policies on foreign income. These external effects provide incentives for strategic behavior in noncooperative international tax competition games, and suggest that global tax coordination may contribute to maximize world welfare.

\section{World-wide Reduction of Factor Income Taxes}

Consider next a simple exercise that illustrates the potential gains from international tax coordination. Assume that both the United States and Europe move together to set factor income taxes at levels dictated by social optimum policies, but still use consumption taxes to finance the transfer targets set in the pre-tax-reform equilibrium. The results of this world-wide tax reform under the same scenarios examined before are reported in Table 4.

With both countries moving together, the incentives for a large capital outflow from the country with unchanged taxes to the country undertaking the tax reform are eliminated. This, however, does not prevent international borrowing and lending from altering the size of the welfare gains, relative to a closed economy, and from affecting the distribution of welfare gains across countries. If $\mathrm{G}$ is kept constant as a share of NDP, the home country welfare gains are 1.01 percent, in the case with $\tau_{b}=0$, and 0.60 percent, when $\tau_{b}$ is set to equate home pre-tax returns on capital and bonds. The corresponding foreign welfare gains are 1.74 and 2.18 percent. As before, the welfare gain of the home country can be smaller for open-economy regimes than in the closed-economy, and the tax on bonds redistributes welfare gains across countries so that a higher tax reduces home welfare and rises foreign welfare. 
In contrast with the unilateral tax reform, the efficiency gains of reducing tax distortions world-wide are so large that the reform fails to cause a welfare loss to either country regardless of how bond interest income is taxed. Relative to a unilateral tax reform under the relative $\mathrm{G}$ rule, the gain of the home country in the world-wide reform is slightly smaller with tax-free bond purchases ( 1.01 percent v. 1.05 percent), but significantly larger with a home-residence-based tax on bonds ( 0.62 percent v. 0.18 percent). The gains in the foreign country are in both cases much larger under the world-wide reform than in the unilateral home tax reform. The gains for the home country are smaller because of a less favorable environment for smoothing consumption, given the higher real interest rates needed during the transition to clear the bond market when tax reforms are undertaken simultaneously in the two economies. The long-run incomeredistribution effect does not cause smaller home welfare gains because the lifetime fall in net foreign assets is smaller with the world-wide tax reform than in the unilateral case (home holdings of foreign bonds fall to -0.36 instead of -0.84 ), and the long-run real interest rate is the same as with a unilateral reform.

In summary, we find that world-wide tax reforms produce significant welfare gains. Depending on how bond purchases are taxed, a country may be somewhat better off with a unilateral tax reform than with a world-wide tax reform. However, this only happens at the expense of a smaller welfare gain abroad. From a world welfare perspective, interpreting (15) with $\phi=1 / 2$ as the pay-off of a cooperative game, world-wide reforms are substantial improvements over unilateral reforms. A formal analysis of the distortions that separate cooperative and noncooperative equilibria is conducted in Section 4.

\section{Sensitivity Analysis}

The results of the numerical analysis of tax reforms depend on the parameters used to describe preferences and technology. Hence it is necessary to examine the sensitivity of the results in response to changes in the various parameters. This is important because the parameterization we selected is a rough approximation based on long-run features of the data, which could be at odds with econometric evidence. Moreover, the values of several parameters are subject of debate even in the econometric literature. ${ }^{28}$

\footnotetext{
${ }^{28}$ See the discussions on labor-leisure elasticities in Lucas (1990), on labor income shares in Cooley and Hansen (1992), and on the intertemporal elasticity of substitution in aggregate consumption and the intratemporal elasticity between traded and nontraded goods in Mendoza (1995).
} 
Table 5 reports results of the sensitivity analysis for the unilateral and world-wide reforms that replace factor income taxes with consumption taxes, both under the relative $G$ rule and assuming $\tau_{b}=0$. The table lists home and foreign welfare gains and the impact and long-run effects of the reforms on home bond holdings, the consumer based real interest rate, consumption of the CES composite good, and leisure. Sensitivity analysis is conducted for 9 alternative parameterizations: (1) inelastic labor, $a=0$, (2) lower intertemporal elasticity of substitution in CES consumption, $\sigma=5$, (3) unitary elasticity of substitution between traded and nontraded goods, $\mu=0$, (4) higher subjective rate of time preference, $B=.965$, or 22 percent long-run real interest rate, (5) faster growth, $\gamma=1.0122$ or 5 percent annually, (6) costless capital adjustment, $\eta=0$, (7) higher labor income shares $\alpha^{\mathrm{T}}=0.75, \alpha^{\mathrm{N}}=.7,(8)$ faster depreciation, $8=0.0356$ or 15 percent per year, and (9) higher initial trade deficit, NX/GDP=-0.15 percent.

In general, the results are in line with Lucas' prediction that welfare gains of tax reforms are in the range $0.75-1.25$ percent. The results are not very sensitive to parameter specifications, except for the cases of higher subjective rate of time preference and faster growth, in which steady-state allocations are altered significantly due to the impact of $B$ and $\gamma$ on long-run capital-output ratios and, in the case of $B$, the long-run real interest rate. For the unilateral (world-wide) reform, home welfare gains range from $0.73(0.7)$ percent, when depreciation is accelerated, to 2.09 (2.1) percent, when the subjective rate of time preference rises. Foreign welfare gains in the unilateral reform range from - .37 percent for the case of higher impatience, to 0.79 percent for the case of faster growth, and in the world-wide reform they range from 0.2 percent when labor is inelastic to near 3 percent with higher impatience. Note that minimum and maximum home welfare gains are obtained under the same parameter structure for both unilateral and world-wide reforms, while for the foreign country the parameterization that results in the smallest gain for the unilateral reform (i.e. higher impatience) is the one that yields the largest gain under the world-wide reform. This asymmetry is also suggestive of the incentives for strategic behavior that may exist in noncooperative tax competition.

\section{International Tax Competition}

This section examines solutions to one-shot international tax competition games under the assumptions that government expenditures follow the relative rule and that there is a long-run public debt 
constraint on lump-sum taxation. Since in this case the first-best social optimum could be recreated with the appropriate mix of taxes, it is straightforward to show that the non-cooperative equilibrium of a game involving all taxes is Pareto efficient. However, since we have shown that this would imply unrealistically large subsidies on labor income, it is more practical to concentrate instead on constrained games. ${ }^{29}$ Thus, we examine games involving capital and consumption tax strategies for given suboptimal labor tax rates. To make the results comparable to those obtained in Section 3, labor tax rates are set equal to the share of NDP absorbed by government in each country, which correspond to the taxes that a world planner not subject to the public debt constraint would set in the social optimum. ${ }^{30}$

\section{Cooperative and Noncooperative Equilibria}

Two types of noncooperative equilibria are considered. First a Nash equilibrium in which, starting from the pre-tax-reform equilibrium, each government sets $\left(\tau_{k}, \tau_{c}\right)$ independently to maximize its households' welfare gain net of transitional dynamics, given the other country's taxes. The Nash equilibrium is a vector $\left(\tau_{k}, \tau_{c}, \tau_{k}{ }^{*}, \tau_{c}{ }^{*}\right)$, and a set of sequences of prices (12) and allocations (13) such that (a) $\left(\tau_{k}{ }^{i}, \tau_{c}{ }^{i}\right)$ for country i maximizes (1) subject to (3) using the pre-tax-reform steady-state allocations of capital and international bonds as initial conditions and taking as given the tax rates of the other country $\left(\tau_{k}{ }^{-i}, \tau_{c}{ }^{-i}\right)$, and (b) for every vector $\left(\tau_{k}, \tau_{c}, \tau_{k}{ }^{*}, \tau_{c}{ }^{*}\right)$, the resulting prices and allocations are a competitive equilibrium. The Nash equilibrium is computed numerically by solving the model--including the iterative routines on foreign bonds and consumption taxes--repeatedly over grids that specify the feasible tax strategies $\tau_{k}{ }^{i}$ and $\tau_{k}{ }^{-i 31}$ The solutions produce a mapping from all feasible $\left(\tau_{k}, \tau_{c}, \tau_{k}{ }^{*}, \tau_{c}{ }^{*}\right)$ strategies into welfare gains net of transitional

\footnotetext{
${ }^{29}$ Competition in all taxes also increases the dimensionality of the problem to the point where numerical solutions, even based on the KPR algorithm, are very inefficient. Experiments where some flexibility is given to labor taxes show that there are interior solutions for capital income taxes in each country's reaction curve (not very sensitive to labor taxes) but the preferred labor tax is always the lowest possible tax or largest possible subsidy.

${ }^{30}$ Alternatively, we could leave labor taxes unchanged at their pre-reform levels or adjust them assuming that factor incomes are taxed uniformly, or that the same tax relief given to capital income is also given to labor income (i.e. the percentage points of the tax reduction is equal for both taxes). The key results of the numerical game-theoretic analysis are not drastically changed by any of these representations.

${ }^{31}$ The grids of tax rates include 50 elements each with various runs trying different spacing settings but maintaining pre-reform tax rates as upper bounds. This implies that the strategy space includes 2500 combinations of home and foreign capital taxes over which the augmented KPR algorithm is executed. The algorithm includes the shooting method on private debt and the iterative routine on the two countries' long-run debt constraints.
} 
dynamics that is then used to construct each country's reaction curve. The intersection of the reaction curves is the Nash equilibrium.

The second noncooperative equilibrium views either the home or the foreign country as a Stackelberg leader. In the Stackelberg equilibrium the leader (country i) chooses its strategy $\left(\tau_{k}{ }^{i}, \tau_{c}{ }^{i}\right)$ so as to maximize the households gain net of transitional dynamics, but internalizing the response of the follower. Thus, country i sets its tax rates to obtain the maximum welfare gain along the follower's reaction curve.

In the Cooperative equilibrium governments act in a coordinated fashion setting tax policies jointly to maximize world welfare. As is common in the literature on policy coordination, the world welfare function is a weighted average of each country's lifetime utility function, as in (15), for arbitrary, nonnegative weights $\phi$. A Cooperative equilibrium relative to $\phi$ is a vector of taxes $\left(\tau_{k}, \tau_{c}, \tau_{k}{ }^{*}, \tau_{c}{ }^{*}\right)$, and the associated sequences of prices and allocations, (12)-(13), such that (a) $\left(\tau_{k}, \tau_{c}, \tau_{k}{ }^{*}, \tau_{c}{ }^{*}\right)$ maximizes (15), and (b) for every $\left(\tau_{k}, \tau_{c}, \tau_{k}{ }^{*}, \tau_{c}{ }^{*}\right)$, the resulting prices and quantities are an intertemporal competitive equilibrium. In particular, we are interested in Cooperative equilibria for values of $\phi$ that constitute Pareto improvements over Nash or Stackelberg equilibria, since this would indicate that international tax coordination is desirable. The efficient Cooperative equilibria are computed numerically by maximizing (15) for a grid of 200 evenlyspaced values of $\phi$ that spans the $(0,1)$ interval, and identifying the values of $\phi$ for which Cooperative outcomes dominate Nash and Stackelberg equilibria.

It is worth noting, following Canzoneri and Henderson (1991), that in the one-shot games studied here Stackelberg and Cooperative equilibria require commitment. In the Stackelberg equilibrium the country that acts as leader must commit credibly to maintain the corresponding tax policy, since in general Stackelberg strategies lie outside the leader's reaction curve. For the Cooperative equilibrium an even higher degree of commitment is needed since both countries are off their reaction curves. Binding international agreements are therefore needed to support these equilibria. Without these agreements the equilibria would also generally be time-inconsistent, even with time-invariant tax rates, because if governments were to reoptimize tax policy at any date during the transition they would formulate different tax strategies. This reoptimization would reflect the fact that the model's long-run bond positions and consumption allocations 
across countries depend on initial conditions, and thus taxes that were optimal at date 0 , with the pre-taxreform allocations as initial conditions, are not optimal at any date after 0 , with corresponding allocations along the transitional dynamics of the original reform as initial conditions.

Another important feature of these games is that the direction of externalities caused by one country's tax strategy on another may be positive or negative depending on the magnitude of the implied price distortions and the associated effects on welfare and tax revenues. This can be inferred from the bell-shaped form of the Laffer curves associated with factor income taxes and the net effects of the smoothing- and debtservice effects discussed earlier (see Mendoza and Tesar (1993) for an analysis of the model's Laffer curves). Solutions of Tax Competition Games: Is Coordination Desirable?

The payoffs and strategies that characterize numerical solutions of international tax competition games are reported in Table 6. The table reports results for the case of a zero tax on bond transactions and a case in which bond purchases are taxed at the same rate as in the experiments of Section 3 . The table also reports each country's Bliss Point strategy, which maximizes one country's welfare assuming the other economy is forced to follow a suboptimal strategy.

Consider first the case of tax-free bond transactions. As Table 6 shows, the payoffs do not differ significantly across the different games, even though tax strategies can differ by as much as 2 percentage points. This is illustrated more clearly in Figure 9, which plots the reaction curves and identifies the location of the different equilibria. The numerical solution of the games involves a complete run of the augmented KPR algorithm for every coordinate in the discretized $\left(\tau_{k}, \tau_{k}{ }^{*}\right)$ space. The optimal strategies, given either home or foreign taxes, determine the points on the corresponding reaction curves.

Figure 9 shows that the reaction curves of this tax competition are very steep, so that optimal tax strategies in each country are not highly dependent on the behavior of the other country. Steep reaction curves imply that, with well-behaved iso-welfare curves, Nash and home- and foreign-leader Stackelberg equilibria (N, $S$, and $S^{*}$ respectively) are likely to be very close. In the limit, if the home reaction curve (R) is vertical and the foreign reaction curve $\left(R^{*}\right)$ is horizontal, the three noncooperative equilibria coincide. With evenly-spaced tax grids that span the interval $(.15, .35)$ in steps of $.004, R$ is vertical and $R^{*}$ is 
horizontal in the neighborhood of the Nash Equilibrium. Thus, the solutions for noncooperative equilibria imply $\mathrm{N}=\mathrm{S}=\mathrm{S}^{*}$, which suggests that the three equilibria in an exact solution are too close to be distinguishable in a numerical approximation.

The fact that international externalities are not very strong within the set of optimal tax strategies represented by reaction curves does not rule out the possibility that cooperative and noncooperative solutions could differ significantly. Differences between these equilibria depend on the curvature of iso-welfare-gain curves in the $\left(\tau_{k}, \tau_{k}{ }^{*}\right)$ space. If these curves are smooth, international externalities could be important as one deviates from reaction curves. However, the small difference in payoffs between the noncooperative and cooperative equilibria suggests that, for the tax strategies corresponding to the core of the contract curve (i.e. those that maximize (15) and are Pareto improvements over noncooperative equilibria, as $E^{0}$ and $E^{1}$ in Figure 9), international externalities continue to play a small role. We conclude, therefore, that while international spillovers of fiscal policies cause large differences in macroeconomic effects of tax reforms between closed and open economies, and between home and foreign countries in open economies, they do not imply strong enough external effects on world relative prices to induce a large wedge between cooperative and noncooperative equilibria. Recall from Figure 7 that even a unilateral tax reform has small effects on the dynamics of real interest rates.

The economic intuition behind the result that Cooperative and Noncooperative equilibria are very similar follows from standard arguments in the literature on policy coordination. In the model, Cooperative equilibria have the potential for improving over noncooperative outcomes to the extent that in the latter policymakers do not consider the indirect, world-general-equilibrium effects of their tax strategies, as explained in Chari and Kehoe (1990). The reason for this is that in the Nash equilibrium the government considers how a change in taxes affects welfare for a given world real interest rate and abstracting from cross-price effects between the world and the domestic real interest and wage rates. The fact that the Cooperative equilibrium incorporates these general equilibrium interactions drives a wedge between the two equilibria similar to a monopoly distortion. The results of the numerical simulation suggest, however, that this monopoly distortion is negligible. 
Chari and Kehoe (1990) also showed in a static model that, unless government expenditures are endogenous and are financed by distortionary taxes, the monopoly distortion disappears as the number of countries grows to infinity and cooperative and noncooperative equilibria coincide. Our model abstracts from an endogenous $\mathrm{G}$ rule that would deliver inefficient noncooperative equilibria in the limiting economies they examine. However, our analysis provides quantitative evidence showing that the initial monopoly distortion, in a dynamic model with two economies of comparable size and distortionary taxes, is very small.

The result that cooperative and noncooperative equilibria are approximately the same disappears if there is a tax on bond purchases. As Table 6 shows, with a home-residence-based tax on bonds at the rate of $1 / 2$ of a percentage point, as in some of the experiments of Tables 3-4, Nash and Stackelberg equilibria are no longer equivalent. In particular, equilibria with either the home or the foreign country as leaders dominate the Nash equilibrium--the difference in welfare is as much as 0.02 percent for the home country and 0.08 percent for the foreign country. Cooperative equilibria for weights in the range $\phi=(.265, .745)$ also dominate the Nash equilibrium, and a subset of this range also dominates home and foreign Stackelberg leadership games. The difference in welfare between Nash and Cooperative equilibria is much larger than in the case with tax-free bond purchases--for the home country the difference can be as much as 0.32 percent and for the foreign country as much as 0.35 percent.

It is worth noting that the tax on bonds does not enter the game because, as shown in Section 2, a long-run, balanced-growth competitive equilibrium requires that this tax be identical in the two countries. By providing solutions for games with alternative values of $\tau_{b}$ we highlight the extent to which cross-country externalities, and hence the differences in pay-offs between cooperative and noncooperative games, depend on the tax on bonds. An analysis that would expand on this work to introduce a grid of common bond taxes could provide further evidence on the level of $\tau_{b}$ that maximizes world welfare for solutions of games over the tax rates $\left(\tau_{\mathrm{k}}, \tau_{\mathrm{c}}, \tau_{\mathrm{k}}{ }^{*}, \tau_{\mathrm{c}}{ }^{*}\right)$. Our limited evidence suggests that $\tau_{\mathrm{b}}=0$ may be the optimal bond tax.

\section{Conclusions}

This paper undertakes a quantitative examination of the positive and normative effects of tax reforms in the context of a two-country, two-sector dynamic equilibrium model of a global economy. The model is 
calibrated to capture the basic features that distinguish fiscal policies in Europe and the United States, assuming standard specifications and parameter values for preferences and technology. In line with recent closed-economy studies, the normative analysis emphasizes the costs of the macroeconomic adjustment implied by the transitional dynamics of the expansion of the capital stock following a reduction in tax distortions. These dynamics are markedly different for open economies because of international externalities that operate via consumption-smoothing and income-redistribution effects transmitted through world capital markets. The consumption-smoothing effect reflects a country's optimal short-term external borrowing to finance the initial investment boom that follows a tax reform. The income-redistribution effect follows from net interest payments on the long-run external debt position to which a country converges after a tax reform. These effects are quantified using a modified version of the linear-approximation method of King, Plosser and Rebelo (1988) that addresses the closed-form indeterminacy of stationary equilibria in a two-country, tax-distorted model of balanced long-run growth. The method is modified to introduce shooting algorithms that determine (a) post-tax-reform steady-state allocations of foreign assets consistent with a path of currentaccount dynamics starting from pre-reform debt positions, and (b) a structure of tax rates, within the timeinvariant class, that satisfies intertemporal budget constraints of governments given targets for expenditures and transfers.

The quantitative analysis begins with a characterization of the model's social optimum and an assessment of the overall welfare costs resulting from distortionary taxation, under alternative policy rules for government expenditures and taxes on world payments. A constrained tax-policy setting is then examined by imposing the condition that government transfers or public debt must meet a predetermined steady-state target. We study the effects resulting from unilateral and world-wide tax reforms aimed at replacing factor income taxes with a higher rate of consumption tax. The analysis illustrates differences in transitional dynamics and in the benefits derived from tax reforms between closed and open economies, and between home and foreign countries in a global economy. As a result of the consumption-smoothing and income-redistribution effects at work in a global economy, the pattern of adjustment of macroeconomic aggregates following a tax reform is markedly different for open economies. Welfare effects, and their 
distribution across countries also differ. Depending on policy rules for government expenditures and taxes on world payments, it is possible for a country undertaking a unilateral reform to derive a smaller gain as an open economy than as a closed economy, and in a global economy it can also transfer must of the benefits of the reform to a foreign country with unchanged taxes. The transition also affects sectoral allocations of productive factors across traded and nontraded sectors and induces temporary fluctuations in real exchange rates and interest differentials.

The numerical methods also provide the means for computing solutions to international tax policy games involving domestic factor income taxes and consumption taxes. Taxes on world payments are required to be identical across countries so as to support long-run world-balanced-growth allocations as a competitive equilibrium. The games that are solved numerically include noncooperative Nash and Stackelberg equilibria and Cooperative equilibria based on an additive world welfare function. If government expenditures are set to remain constant relative to the size of the economy, and if the target for long-run transfers is expressed as a share of GDP, the monopoly distortion that drives a wedge between cooperative and noncooperative equilibria is negligible as long as international payments are not taxed. Noncooperative equilibria become increasingly inefficient as taxes on foreign interest income are raised. Thus, international tax coordination is required either to establish a zero tax rate on world payments, or, with non-zero taxes on net foreign payments, to produce the taxes on domestic income and consumption that yield efficient equilibria.

We conclude that, while Lucas' (1990) assertion that a sound tax reform can produce sizable social welfare gains still holds, in an open economy it is not necessarily true that these gains constitute a "free lunch." The international externalities quantified in this paper show that the outcome of tax reforms undertaken by countries in a global economy is significantly affected by other fiscal policy objectives (involving government expenditures and transfer policies), by decisions on the extent to which international capital flows are subject to taxation, and by the interaction of independent fiscal authorities with strategic behavior. Exploiting the benefits of tax reforms to a maximum thus requires some international coordination of fiscal policies. 
$-36-$

In the final analysis, our results reflect Pigou's (1947) intuition that, when international relations are considered, "it may be feasible for a man subjected to taxation in a taxed area to make use of an untaxed area in such a way as to reduce the fiscal burden imposed upon him." (p. 165). Further research on how our quantitative results are altered by distributional issues across generations and income groups, by the introduction of stochastic shocks or policy uncertainty, and by endogenous government expenditure choices, all of which have been found to play a role in theoretical work, would be worth pursuing. 


\section{References}

Arvanitis, Athanasios V., (1993), "Taxing Capital in an Open Economy Model," mimeo, University of Rochester.

Backus, David K., Michael Devereux and Douglas Purvis (1988), "A Positive Theory of Fiscal Policies in Open Economies," in International Aspects of Fiscal Policy, ed. by Jacob Frenkel, U. of Chicago Press (for NBER), Chicago.

Backus, David K., Finn E. Kydland and Patrick J. Kehoe (1992), "International Real Business Cycles," Journal of Political Economy, vol. 100, 745-775.

Baxter, Marianne and Robert G. King (1993), "Fiscal Policy in General Equilibrium," American Economic Review vol.83, no. 3, 315-334.

and Mario J. Crucini (1993), "Business Cycles and the Asset Structure of Foreign Trade," mimeo, University of Rochester.

Bernheim, B. Douglas (1981), "A Note on Dynamic Tax Incidence," Quarterly Journal of Economics, vol. 96, 705-723.

Bovenberg, A. Lans (1989) "The Effects of Capital Income Taxation on International Competitiveness and Tax Flows," American Economic Review v. 79, no. 5, 1045-1064.

Calvo, Guillermo A. and Maurice Obstfeld (1988), "Optimal Time-Consistent Fiscal Policy with Finite Lifetimes," Econometrica, vol. 56, 411-432.

Canzoneri, Matthew B. and Dale W. Henderson (1991), Monetary Policy in Interdependent Economies: A Game-Theoretic Approach, MIT Press, Cambridge, MA.

Chamley, Christophe P. (1981), "The Welfare Cost of Capital Income Taxation in a Growing World Economy," Journal of Political Economy, vol. 89, 468-496.

(1986), "Optimal Taxation of Capital Income in General Equilibrium with Infinite Lives," Econometrica, vol. 54, 607-622.

Chari, V. V., and Patrick J. Kehoe (1990), "International Coordination of Fiscal Policies in Limiting Economies," Journal of Political Economy, vol. 98, 617-636.

Chari, V. V., Lawrence J. Christiano, and Patrick J. Kehoe (1994) "Optimal Fiscal Policy in a Business Cycle Model," Journal of Political Economy, vol. 102, no. 4, 617-52.

Cooley, Thomas F., and Gary D. Hansen (1992), "Tax Distortions in a Neoclassical Monetary Economy," Journal of Economic Theory, vol. 58, 290-316.

Correia, Isabel, (1993), "Optimal Taxation in a Small Open Economy," mimeo, Bank of Portugal.

Feldstein, Martin (1976), "On the Theory of Tax Reform," Journal of Public Economics, vol. 6, 77-104.

Frenkel, Jacob A., and Assaf Razin (1992), Fiscal Policies and the World Economy: An Intertemporal Approach, second edition(Cambridge, Mass.: MIT Press). 
Frenkel, Jacob A., Assaf Razin and Efraim Sadka (1991) International Taxation in an Integrated World (Cambridge, Mass: MIT Press).

Greenwood, Jeremy and Gregory W. Huffman, (1991) "Tax Analysis in a Real-Business-Cycle Model," Journal of Monetary Economics, vol. 27, 167-190.

Harberger, Arnold C. (1964) "The Measurement of Waste," American Economic Review, vol. LIV, 58-76.

Froot, Kenneth A. and Kenneth Rogoff (1995), "Perspectives on PPP and Long-Run Real Exchange Rates,"Handbook of International Economics, vol. 3, edited by Gene Grossman and Kenneth Rogoff, North Holland Press, Amsterdam.

International Monetary Fund (1992), "Tax Harmonization in the European Community: Policy Issues and Analysis," Occasional Paper no. 94, Washington, D.C.

Jones, Larry E., Rodolfo E. Manuelli, and Peter E. Rossi (1993), "Optimal Taxation in Models of Endogenous Growth," Journal of Political Economy, vol. 101, 485-517.

Kehoe, Patrick J., (1987), "Coordination of Fiscal Policies in a World Economy," Journal of Monetary Economics, vol. 19, 349-376.

King, Robert J., Charles I. Plosser and Sergio T. Rebelo (1988) "Production, Growth and Business Cycles: I. The Basic Neoclassical Model," Journal of Monetary Economics 21 (March/May) 195-232.

and Sergio T. Rebelo, "Public Policy and Economic Growth: Developing Neoclassical Implications," Journal of Political Economy, vol. 98, s126-s150.

Lipton, David, James Poterba, Jeffrey Sachs and Lawrence Summers (1982), "Multiple Shooting in Rational Expectations Models," Econometrica, vol. 50, no. 5, 1329-1333.

and Jeffrey Sachs (1983), "Accumulation and Growth in a Two-Country Model: A Simulation Approach," Journal of International Economics, vol 15, 135-159.

Lucas Jr., Robert E. and Nancy L. Stokey (1983), "Optimal Fiscal and Monetary Policy in an Economy without Capital," Journal of Monetary Economics, vol. 12, 55-93.

(1987), Models of Business Cycles, Basil Blackwell, New York, NY.

(1990) "Supply-Side Economics: An Analytical Review," Oxford Economic Papers, 42, 293-316.

Mendoza, Enrique G. (1991), "Real Business Cycles in a Small Open Economy," American Economic Review, vol.81, 797-818.

(1995), "The Terms of Trade, The Real Exchange Rate, and Economic Fluctuations," International Economic Review, vol. 36, 101-137.

Assaf Razin, and Linda L. Tesar (1994), "Effective Tax Rates in Macroeconomics: Cross Country Estimates of Tax Rates on Factor Incomes and Consumption," Journal of Monetary Economics, vol. 34, 297 323. 
-39 .

and Linda L. Tesar (1993), "Supply-Side Economics in an Integrated World Economy ", IMF Working Paper No. 93/81 , International Monetary Fund, Washington D.C.

Milesi-Ferretti, Gian Maria and Nouriel Roubini (1994), "Taxation and Endogenous Growth in Open Economies," IMF Working Paper WP/94/97, International Monetary Fund, Washington D.C.

Obstfeld, Maurice and Kenneth Rogoff (1994), "Foundations of International Macroeconomics," unpublished manuscript.

Ostry, Jonathan D. and Carmen M. Reinhart (1992), "Private Saving and Terms of Trade Shocks", IMF Staff Papers, vol.39, 495-517.

Pigou, A.C., (1947), A Study in Public Finance, Macmillan \& Co. Ltd, London, 3rd edition.

Ramsey, F.P., (1927), "A Contribution of the Theory of Taxation," Economic Journal, vol.37, 47-61.

Razin, Assaf and Efraim Sadka (1989), "International Tax Competition and Gains from Tax Harmonization," NBER Working Paper No. 3152.

and Efraim Sadka (1991), "Vanishing Tax on Capital Income in the Open Economy," NBER Working Paper No. 3796.

and Efraim Sadka (1992), "The Economy of Modern Israel: Malaise and Promise," Discussion Paper No. 7-92, Pinhas Sapir Center for Development, Tel-Aviv University, June.

and Chi-Wa Yuen (1993), "Convergence in Growth Rates: The Role of Capital Mobility and International Taxation," in Capital Mobility: New Perspectives, ed. by A. Razin and L. Leiderman, Cambridge University Press.

Rebelo, Sergio T. (1991), "Long-Run Policy Analysis and Long-Run Growth ,"Joumal of Political Economy, vol. 99, no. 3, 439-482.

Sibert, Ann, (1990) "Taxing Capital in a Large, Open Economy," Journal of Public Economics, vol. 41, $297-$ 317.

Stockman, Alan C. and Linda L. Tesar (1995) "Tastes and Technology in a Two-Country Model of the Business Cycle: Explaining International Co-Movements," forthcoming in the American Economic Review.

Stokey, Nancy L. and Sergio T. Rebelo (1993) "Growth Effects of Flat Tax Rates," NBER Working Paper No. 4426.

Stuart, Charles, (1984), "Welfare Costs per Dollar of Additional Tax Revenue in the United States," American Economic Review, vol. 74, no. 3, 352-362 


\section{Appendix}

Proposition I. Given iso-elastic preferences and technology as in (2) and (6), and if government policy is to maintain expenditures $G_{t}$ constant as a share Sgg of net domestic product at any date $t$, then:

(a) Under unrestricted taxes and lump-sum transfers, the social optimum equilibrium is recreated by setting time-invariant tax rates $\tau_{k}=\tau_{n}=S g g$ and $\tau_{c}=0$, providing a depreciation allowance, and setting transfers $T_{i}=0$ for all $t$.

(b) Under a tax system restricted so that the steady-state tax revenue finances Sgg and a fixed share of government transfers in GDP (defined as $S t$ ), the social optimum, first-best equilibrium is recreated by setting the time-invariant tax rates $\tau_{k}=S g g, \tau_{c}=S t /(S c-\alpha(1-S g g))$, and $\tau_{n}=S g g-(1-S g g) \tau_{c}$, where $S c$ is the steady-state GDP share of consumption, providing a depreciation allowance, and setting transfers to follow the rule $T_{t}=\tau_{c} C_{t}+\alpha\left(\tau_{n}-S g g\right) F\left(K_{v}, N\right)$ for all $t$.

Proof: The proof begins by characterizing the social optimum and the competitive equilibrium. Then the competitive equilibrium under unrestricted taxation is examined to show that tax policy (a) produces the same equilibrium as the social optimum. The proof of (b) follows a similar strategy but imposing the restricted taxation framework. For simplicity the proof is based on a closed-economy model with one good and no adjustment costs. Similar results are obtained for the two-sector, open-economy model.

1. The Social Optimum.

In the social optimum, a planner chooses $C_{t}, L_{t}, N_{t}$ and $K_{t+1}$ for $t=0, \ldots, \infty$ to maximize

$$
\left[\sum_{t \rightarrow 0} \beta^{t} U\left(C_{t} L_{t}\right)\right]
$$

subject to:

$$
F\left(K_{f} N_{t}\right)-C_{t}+\gamma K_{t+1}-(1-8) K_{t}+S g g\left(F\left(K_{t} N_{t}\right)-8 K_{t}\right)
$$

The first-order conditions of this problem are:

$$
\begin{gathered}
\frac{U_{L}(t)}{U_{C}(t)}=(1-s g g) F_{N}(t) \\
\gamma U_{C}(t)=\beta U_{C}(t+1)\left[(1-s g g)\left(F_{K^{\prime}}(t+1)-\delta\right)+1\right] \\
C_{t}=(1-s g g)\left(F\left(K_{t} N_{t}\right)-\delta K_{t}\right)-\gamma K_{t+1}+K_{t}
\end{gathered}
$$

which in the steady state can be rewritten as: 


$$
\begin{gathered}
-41- \\
\frac{N}{1-N}=\frac{(1-S g g) \alpha}{a S c} \\
S k=\frac{\beta(1-\alpha)(1-S g g)}{\gamma-\beta[1-\delta(1-S g g)]} \\
S c=(1-S g g)(1-\delta S)-(\gamma-1) S k
\end{gathered}
$$

2. The Competitive Equilibrium

In a competitive equilibrium households maximize (A1) subject to:

$$
\left(1+\tau_{d}\right) C_{t}=\left(1-\tau_{n}\right) \omega_{t} N_{t}+\left(1-\tau_{k}\right)\left(r_{t}-8\right) K_{t}-\gamma K_{t+1}+K_{t}+T_{t}
$$

taking as given tax rates, transfers, and the real returns on capital and labor. The competitive equilibrium is characterized by the first-order conditions of the households' problem with the addition of the government budget constraint, the firms' zero-profits conditions, and the market-clearing conditions. After some manipulation, the competitive equilibrium is characterized by the following conditions:

$$
\begin{gathered}
\frac{U_{L}(t)}{U_{C}(t)}=\left(\frac{1-\tau_{n}}{1+\tau_{c}}\right) F_{N}(t) \\
\gamma U_{C}(t)=\beta U_{C}(t+1)\left[\left(1-\tau_{k}\right)\left(F_{K}(t+1)-\delta\right)+1\right] \\
C_{t}=(1-S g g)\left(F\left(K_{p} N\right)-\delta K_{t}\right)-\gamma K_{t+1}+K_{t}
\end{gathered}
$$

which in the steady state can be rewritten as:

$$
\begin{gathered}
\frac{N}{1-N} \cdot\left(\frac{1-\tau_{n}}{1+\tau_{c}}\right) \frac{\alpha}{a S_{c}} \\
S k=\frac{\beta(1-\alpha)\left(1-\tau_{k}\right)}{\gamma-\beta\left[1-\delta\left(1-\tau_{k}\right)\right]} \\
S c=(1-S g g)(1-\delta S k)-(\gamma-1) S k
\end{gathered}
$$


3. Optimal Policies under Unrestricted Taxation

Comparing (A3)-(A5) to (A10)-(A12) and (A6)-(A8) to (A13)-(A15), and since the initial conditions are the same in both problems, it follows that the tax rates set in (a) would produce the same intertemporal allocations, and hence that policy (a) is Pareto optimal. Replacing the tax rates in the government's budget constraint yields:

$$
S g g\left[\omega N_{t}+K_{t}\right]-S g g \delta K_{t}=G_{t}+T_{t}
$$

Hence it follows that, since $G_{t}=\operatorname{Sgg}\left(F\left(K_{t}, N_{t}\right)-8 K_{t}\right)$ and $F(K, N)$ is CRS, $T_{t}=0$ for all $t$ in this optimal policy. 4. Optimal Policies under the Lung-Run Transfers Constraint

Following a similar strategy as above, comparing (A3)-(A5) to (A10)-(A12) and (A6)-(A8) to (A13)(A15), and since initial conditions are the same in both problems, it follows that any tax strategy $\left(\tau_{b} \tau_{c}, \tau_{n}\right)$ such that (i) $\tau_{k}=S g g$ and (ii) $\left(1-\tau_{n}\right) /(1+\tau)=1-S g g$, would produce the same intertemporal allocations as the social optimum. However, since the long-run transfers constraint restricts the choice of tax rates in this case, the triple $\left(\tau_{b} \tau_{c}, \tau_{n}\right)$ must also satisfy the government's budget constraint given Sgg and St. After some manipulation, the steady-state government's budget constraint expressed in terms of GDP shares can be expressed as follows:

$$
\alpha \tau_{n}+(1-\alpha) \tau_{k}-8 S k \tau_{k}+S c \tau_{c}=S g g[1-\delta S k]+S t
$$

Equation (A17) together with (i) and (ii) is a three-equation system that determines the triple $\left(\tau_{b} \tau_{c}, \tau_{n}\right)$ that recreates the social optimum under the long-run transfers constraint as defined in (b).

The proof is completed by determining the intertemporal path of transfers that balances the government's budget off the steady state. By comparing the steady-state government budget constraint (A17) with its corresponding off-steady-state version, it follows the GDP share of transfers during the transition deviates from the long-run share so as to rebate to households any excess tax revenue resulting from positive deviations from steady-state of the consumption-GDP ratio, or imposing a lump-sum tax to finance tax revenue shortfalls if $\mathrm{Sc}_{\mathrm{t}}$ falls below the steady state:

$$
S t_{t}-S t=\tau_{c}\left(S c_{t}-S c\right)
$$

Thus, lump-sum transfers during the transition finance any surplus of shortfall in the GDP share of consumption tax revenue. The path of transfers defined in (b) follows from (A18) after simple algebraic transformations. 
Table 1

Steady-State Allocations and Fiscal Policy Parameters

\begin{tabular}{|c|c|c|}
\hline \multicolumn{2}{|c|}{ United States } & European G-4 \\
\hline Data & Model & Data \\
\hline
\end{tabular}

\section{Shares of GDP}

Consumption

0.65

0.57

0.60

0.53

Investment (a)

0.16

0.25

0.17

0.27

Govt. Exp. (b)

0.19

0.19

0.21

0.21

Net Exports

0.01

0.01

Tax Revenues

0.28

0.29

0.36

0.38

Transfers (c)

0.14

0.11

0.24

0.18

Tax Rates (d)

$\tau_{\mathrm{c}}$

$\tau_{\mathrm{n}}$

$\tau_{k}$

$\underline{\text { Ratios (e) }}$

$\mathrm{y}^{\mathrm{T}} / \mathrm{y}^{\mathrm{N}}$

1.36

5.8

5.8

16.0

16.0

28.5

28.5

39.0

39.0

43.0

43.0

32.8

32.8

$y / y^{*}$

1.32

Notes: All data, except tax revenue and government transfers, from $O E C D$ Quarterly National Accounts. Tax revenue and government transfers are averages of annual data obtained from OECD National Accounts and OECD Revenue Statistics. Columns 2 and 4 are the outcomes of the model in the pre-reform steady state.

a. Private investment data are not available for Italy. The figure shown is the average investment share in France, Germany and the United Kingdom.

b. Government expenditures (including public investment) at the federal, state and local levels.

c. Subsidies and other current transfers. Data for the Italy and the United Kingdom are averaged over the $1980-88$ period.

d. Tax rates from Mendoza, Razin, and Tesar (1994). Capital and consumption tax rates are time-series averages, labor income tax rates are 1988 point estimates.

e. Actual ratios computed using 1975 sectoral GDP shares and per capita GDP in international dollars from Tables 6.2 and 1.7 in Kravis, Heston, and Summers (1992). 
Table 2

Macroeconomic Effects of Distortionary Taxation 1/

(percentage changes or basis point changes under social optimum policies relative to levels under current policies)

\begin{tabular}{|c|c|c|c|c|c|c|c|c|c|c|}
\hline \multirow[b]{3}{*}{ Variable } & \multirow{2}{*}{\multicolumn{2}{|c|}{ Closed Economy }} & \multicolumn{4}{|c|}{ Open Economy $(\mathrm{tb}=0)$} & \multicolumn{4}{|c|}{ Open Economy $(t b>0)$} \\
\hline & & & \multicolumn{2}{|c|}{ Home Country } & \multicolumn{2}{|c|}{ Foreign Country } & \multicolumn{2}{|c|}{ Home Country } & \multicolumn{2}{|c|}{ Foreign Country } \\
\hline & Optimum & $\begin{array}{l}\text { Current } \\
\text { Policies }\end{array}$ & $\begin{array}{l}\text { Social } \\
\text { Optimum }\end{array}$ & $\begin{array}{l}\text { Current } \\
\text { Policies }\end{array}$ & $\begin{array}{l}\text { Social } \\
\text { Optimum }\end{array}$ & $\begin{array}{l}\text { Current } \\
\text { Policies }\end{array}$ & $\begin{array}{l}\text { Social } \\
\text { Optimum }\end{array}$ & $\begin{array}{l}\text { Current } \\
\text { Policies }\end{array}$ & $\begin{array}{l}\text { Social } \\
\text { Optimum }\end{array}$ & $\begin{array}{l}\text { Current } \\
\text { Policies }\end{array}$ \\
\hline \multicolumn{11}{|c|}{ A) Relative G Rule } \\
\hline \multirow{2}{*}{\multicolumn{11}{|c|}{$\begin{array}{l}\text { Percentage changes } \\
\text { Welfare } 2.492\end{array}$}} \\
\hline Welfare & 2.492 & & 2.435 & & 5.024 & & & & & \\
\hline GDP & 27.323 & & 27.323 & & 38.473 & & 2.333 & & 5.132 & \\
\hline $\mathrm{C}$ & 19.853 & & 19.853 & $\because$ & 35.838 & & 27.500 & & 38.110 & \\
\hline K & 47.617 & & 47.767 & : & 45.382 & & 19.853 & & 35.838 & \\
\hline RER & -2.145 & & -2.145 & & -0.679 & & 47.878 & & 45.243 & \\
\hline Basis poir & anges & & & & -0.018 & & -2.145 & & -0.679 & \\
\hline NX/GDP & -- & & 0.073 & 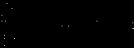 & -0.076 & & & & & \\
\hline I/GDP & 3.951 & & 3.949 & & 1.383 & & $\begin{array}{l}0.140 \\
3.947\end{array}$ & & -0.147 & \\
\hline $\mathbf{R}$ & 0.000 & & 0.000 & & 0.000 & & $\begin{array}{r}3.941 \\
-0.772\end{array}$ & & 1.354 & \\
\hline$L$ & -3.200 & & -3.196 & & -5.883 & & $\begin{array}{l}-0.7 / 2 \\
-3.206\end{array}$ & & -0.772 & \\
\hline tk & -19.792 & & -19.792 & & -7.208 & & $\begin{array}{r}-3.206 \\
-19.792\end{array}$ & & -5.862 & \\
\hline tn & -5.292 & & -5.292 & & -13.483 & & -5.292 & & -7.208 & \\
\hline tc & -5.770 & & -5.770 & & -16.003 & & $\begin{array}{l}-3.292 \\
-5.770\end{array}$ & & -13.483 & \\
\hline tb & - & & 0.000 & 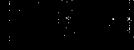 & 0.000 & & -0.758 & & $\begin{array}{r}-16.003 \\
-0.758\end{array}$ & \\
\hline \multicolumn{10}{|c|}{ B) Absolute G Rule } & \\
\hline Percentag & anges & & & & & & & & & \\
\hline Welfare & 12.867 & & 12.972 & & 20.513 & & & & & \\
\hline GDP & 75.965 & & 75.614 & & 101.807 & & 12.934 & & 20.558 & \\
\hline C & 58.741 & & 58.974 & & 87.088 & & 75.923 & & 101.807 & \\
\hline K & 128.609 & & 128.212 & & $\begin{array}{r}140864 \\
14080\end{array}$ & & 58.974 & & 87.088 & \\
\hline RER & -3.753 & & -3.753 & & 140.804 & & 128.266 & & 140.744 & \\
\hline \multirow{2}{*}{\multicolumn{10}{|c|}{$\begin{array}{l}\text { Basis point changes } \\
\text { NX/GDP }\end{array}$}} & \\
\hline NX/GDP & -- & & -0.174 & & & & & & & \\
\hline |/GDP & 7.379 & & 7.384 & & 5.183 & & -0.134 & & 0.124 & \\
\hline $\mathbf{R}$ & 0.000 & & 0.000 & & 0.000 & & 7.383 & & 5.184 & \\
\hline$L$ & -7.744 & & -7.696 & & -10.533 & & -1.287 & & -1.287 & \\
\hline tk & -43.000 & & -43.000 & & -32750 & & -7.703 & & -10.525 & \\
\hline $\operatorname{tn}$ & -28.500 & & -28.500 & & $\begin{array}{l}-32.150 \\
-39025\end{array}$ & & -43.000 & & -32.750 & \\
\hline tc & -5.770 & & -5.770 & & $\begin{array}{l}-39.025 \\
-16.003\end{array}$ & & -28.500 & & -39.025 & \\
\hline tb & -- & & 0.000 & & 0.000 & & $\begin{array}{l}-5.770 \\
-1.265\end{array}$ & & $\begin{array}{r}-16.003 \\
-1265\end{array}$ & \\
\hline
\end{tabular}

1/ Figures under social optimum are percentage or basis point changes in steady-state, balanced-growth allocations relative to levels under current policies,
which are shown in shaded blocks. Welfare changes include the

which are shown in shaded blocks. Welfare changes include the cost of transitional dynamics. GDP, C, and K are in units of the traded good. 
Table 3

Macroeconomic Effects of Unilateral Tax Reform Replacing Income Taxes with Consumption Tax1/ (percentage and basis point changes relative to levels under current policies in Table 2)

\begin{tabular}{|c|c|c|c|c|c|}
\hline \multirow[b]{2}{*}{ Variable } & \multirow[t]{2}{*}{ Closed Economy } & \multicolumn{2}{|c|}{ Open Economy $(t b=0)$} & \multicolumn{2}{|c|}{ Open Economy $(\mathrm{tb}>0)$} \\
\hline & & Home Country & Foreign Country & Home Country & Foreign Country \\
\hline \multicolumn{2}{|c|}{ A) Relative G and T Rules } & & & & \\
\hline \multicolumn{6}{|c|}{ Percentage changes } \\
\hline Welfare & 1.057 & 1.052 & -0.163 & 0.178 & 0.611 \\
\hline GDP & 10.125 & 11.512 & -1.832 & 11.528 & -2.896 \\
\hline C & 3.922 & 3.186 & 0.578 & 2.206 & 0.578 \\
\hline $\mathrm{K}$ & 27.824 & 29.279 & -1.764 & 29.103 & -2.578 \\
\hline RER & -2.145 & -2.145 & 0.000 & -2.145 & 0.000 \\
\hline \multicolumn{6}{|c|}{ Basis point changes } \\
\hline NXGDP & -- & 1.021 & -1.272 & 1.505 & -1.885 \\
\hline I/GDP & 3.951 & 3.921 & 0.065 & 3.908 & 0.051 \\
\hline $\mathbf{R}$ & 0.000 & 0.000 & 0.000 & -0.772 & -0.772 \\
\hline $\mathrm{L}$ & -0.073 & -0.329 & 0.342 & -0.309 & 0.503 \\
\hline th & -19.792 & -19.792 & 0.000 & -19.792 & 0.000 \\
\hline $\operatorname{tn}$ & -5.292 & -5.292 & 0.000 & -5.292 & 0.000 \\
\hline tc & 14.387 & 14.767 & 0.000 & 15.966 & 0.000 \\
\hline tb & - & 0.000 & 0.000 & -0.758 & -0.758 \\
\hline \multicolumn{6}{|c|}{ B) Absolute $G$ and T Rules } \\
\hline \multicolumn{6}{|c|}{ Percentage changes } \\
\hline Welfare & 9.117 & 9.078 & -0.815 & 9.030 & -0.783 \\
\hline GDP & 41.579 & 45.088 & -4.418 & 45.343 & -4.418 \\
\hline $\mathrm{C}$ & 27.739 & 26.573 & 0.549 & 26.573 & 0.549 \\
\hline $\mathrm{K}$ & 83.903 & 88.198 & -4.069 & 88.195 & -4.117 \\
\hline RER & -3.753 & -3.753 & 0.000 & -3.753 & 0.000 \\
\hline \multicolumn{6}{|c|}{ Basis point changes } \\
\hline NX/GDP & -- & 2.268 & -3.923 & 2.307 & -3.968 \\
\hline I/GDP & 7.379 & 7.321 & 0.080 & 7.320 & 0.081 \\
\hline $\mathbf{R}$ & 0.000 & 0.000 & 0.000 & -1.287 & -1.287 \\
\hline $\mathrm{L}$ & -3.133 & -3.637 & 0.596 & -3.640 & 0.603 \\
\hline tk & -43.000 & -43.000 & 0.000 & -43.000 & 0.000 \\
\hline $\operatorname{tn}$ & -28.500 & -28.500 & 0.000 & -28.500 & 0.000 \\
\hline tc & 26.041 & 26.289 & 0.000 & 26.323 & 0.000 \\
\hline tb & 0.000 & 0.000 & 0.000 & -1.265 & -1.265 \\
\hline
\end{tabular}

1/Unilateral tax reform sets tk and tn to the corresponding tax rates under social optimum policies, and tc to the level needed to finance the pre-tax-reform, steady-state GDP ratio (Case A) or real level (Case B) of government transfers. All units are as in Table 2. 
Table 4

Macroeconomic Effects of Global Tax Reform Replacing Income Taxes with Consumption Taxes1/ (percentage and basis point changes relative to levels under current policies in Table 2)

\begin{tabular}{llll}
\hline \multirow{3}{*}{ Variable } & \multirow{2}{*}{ Open Economy (tb $=0)$} & \multicolumn{2}{c}{ Open Economy (tb $>0$ ) } \\
\cline { 3 - 4 } \cline { 4 - 5 } & Home Country Foreign Country & Home Country Foreign Country \\
\hline
\end{tabular}

A) Relative $G$ and T Rules

Percentage changes

$\begin{array}{crr}\text { Welfare } & 1.057 & 1.012 \\ \text { GDP } & 10.125 & 10.818 \\ \text { C } & 3.922 & 3.431 \\ \text { K } & 27.824 & 28.472 \\ \text { RER } & -2.145 & -2.145 \\ \text { Basis point changes } & & \\ \text { NX/GDP } & - & 0.460 \\ \text { IGDP } & 3.951 & 3.938 \\ \text { R } & 0.000 & 0.000 \\ \text { L } & -0.073 & -0.182 \\ \text { tk } & -19.792 & -19.792 \\ \text { tn } & -5.292 & -5.292 \\ \text { tc } & 14.387 & 14.557 \\ \text { tb } & - & 0.000\end{array}$

\subsection{8 \\ 9.008 \\ 7.803 \\ 14.470 \\ $-0.679$}

$-0.514$

1.396

0.000

$-0.953$

$-7.208$

$-13.483$

18.057

0.000
0.621

10.833

3.186

28.389

$-2.145$

0.665

3.932

$-0.772$

$-0.166$

$-19.792$

$-5.292$

15.073

$-0.758$
2. 181

8.841

8.382

14.538

$-0.679$

$-0.741$

1.371

$-0.772$

$-0.958$

$-7.208$

$-13.483$

17.479

$-0.758$

B) Absolute G and T Rules

Percentage changes

Welfare

GDP

C

K

RER

Basis point changes

NX/GDP

I/GDP

$\mathrm{R}$

L

tk

tn

tc

tb

$\begin{array}{rr}9.117 & 9.123 \\ 41.579 & 41.579 \\ 27.739 & 27.739 \\ 83.903 & 83.947 \\ -3.753 & -3.753 \\ & \\ -- & 0.014 \\ 7.379 & 7.380 \\ 0.000 & 0.000 \\ -3.133 & -3.138 \\ -43.000 & -43.000 \\ -28.500 & -28.500 \\ 26.041 & 26.030 \\ 0.000 & 0.000\end{array}$

15.170

55.020

43.956

84.998

$-2.446$

$-0.018$

5.188

0.000

$-5.047$

$-32.750$

$-39.025$

23.201

0.000
9.081

41.828

27.739

83.943

$-3.753$

0.053

7.378

$-1.287$

$-3.140$

$-43.000$

$-28.500$

26.073

$-1.265$
15.215

55.020

43.956

84.930

$-2.446$

$-0.061$

5.189

$-1.287$

$-5.043$

$-32.750$

$-39.025$

23.167

$-1.265$

$1 /$ Global tax reform sets $t k, t n, k^{*}$, and $t^{*}$ to the corresponding tax rates under social optimum policies, and $t c$ and $t^{*}$ to the levels needed to finance the pre-tax-reform, steady-state GDP ratios (Case A) or real levels (Case B) of governme transfers in each country. All units are as in Table 2. 
Table 5

Sensitivity Analysis for the Reform Eliminating Factor Income Taxation 1/

(based on model with tax-free bond purchases and relative $G$ rule)

\begin{tabular}{|c|c|c|c|c|c|c|c|c|c|c|c|c|c|c|c|c|c|c|c|c|}
\hline \multirow{3}{*}{$\begin{array}{l}\text { Model } \\
\text { Economy }\end{array}$} & \multirow{2}{*}{\multicolumn{6}{|c|}{$\begin{array}{l}\text { Unilateral Reform } \\
\text { Impact Effects }\end{array}$}} & & \multicolumn{10}{|c|}{ World-wide Reform } \\
\hline & & & & & & & & & & & \multicolumn{2}{|c|}{ Welfare Gains } & \multicolumn{4}{|c|}{ Impact Effects } & \multicolumn{4}{|c|}{ Long-Run Effects } \\
\hline & Home & Foreign & $B$ & Rc & CES & $\bar{L}$ & \multicolumn{4}{|c|}{$\begin{array}{l}\text { Long-Run Effects } \\
\text { Rc CES }\end{array}$} & Home & Foreign & $\bar{B}$ & $\mathrm{Rc}$ & CES & $L$ & $\mathrm{~B}$ & $\mathrm{Rc}$ & CES & $L$ \\
\hline $\begin{array}{l}\text { Inelastic labor supply } \\
\qquad(a=0)\end{array}$ & 0.878 & 0.047 & -0.189 & 1.547 & 0.649 & 0.000 & -3.235 & 1.706 & 0.700 & 0.000 & 0.862 & 0.201 & -0.086 & 1.602 & 0.643 & 0.000 & -2.180 & 1.706 & 0.704 & 0.000 \\
\hline $\begin{array}{l}\text { Lower Intertemporal } \\
\text { substitution } \\
\qquad(\text { sigma }=5)\end{array}$ & 0.870 & -0.308 & -0.020 & 1.568 & 0.131 & 0.805 & -0.898 & 1.706 & 0.142 & 0.796 & 0.784 & 1.569 & 0.004 & 1.650 & 0.131 & 0.803 & -0.397 & 1.706 & 0.142 & 0.798 \\
\hline $\begin{array}{l}\text { Unitary atemporal } \\
\text { substitution } \\
\qquad(m u=0)\end{array}$ & 1.061 & -0.171 & -0.023 & 1.569 & 0.225 & 0.802 & -0.854 & 1.706 & 0.245 & 0.797 & 1.022 & 1.740 & 0.002 & 1.651 & 0.223 & 0.799 & -0.370 & 1.706 & 0.246 & 0.798 \\
\hline $\begin{array}{l}\text { Higher impatience } \\
\quad(\text { beta }=0.965)\end{array}$ & 2.093 & -0.366 & -0.025 & 4.845 & 0.081 & 0.832 & -0.465 & 5.170 & 0.093 & 0.824 & 2.121 & 2.995 & -0.001 & 5.098 & 0.080 & 0.827 & -0.164 & 5.170 & 0.094 & 0.829 \\
\hline $\begin{array}{l}\text { Faster growth } \\
\text { (gamma }=1.0122) 2 /\end{array}$ & 2.092 & 0.788 & -0.018 & 1.564 & 0.127 & 0.791 & -0.858 & 1.706 & 0.139 & 0.786 & 2.060 & 2.548 & 0.004 & 1.641 & 0.126 & 0.788 & -0.403 & 1.706 & 0.139 & 0.787 \\
\hline $\begin{array}{c}\text { Costless investment } \\
\qquad(\mathrm{eta}=0)\end{array}$ & 1.060 & -0.172 & -0.102 & 1.564 & 0.130 & 0.802 & -0.814 & 1.706 & 0.142 & 0.797 & 1.017 & 1.737 & -0.025 & 1.647 & 0.129 & 0.798 & -0.354 & 1.706 & 0.142 & 0.798 \\
\hline $\begin{array}{l}\text { Higher labor shares } \\
\text { (alphaT }=.75 \text {, alphaN }=.7)\end{array}$ & 0.740 & -0.083 & -0.007 & 1.542 & 0.071 & 0.786 & -0.228 & 1.706 & 0.075 & 0.784 & 0.726 & 1.949 & 0.005 & 1.650 & 0.071 & 0.783 & -0.076 & 1.706 & 0.076 & 0.785 \\
\hline $\begin{array}{l}\text { Faster depreciation } \\
\qquad(\text { dell } a=.0356) 3 /\end{array}$ & 0.735 & -0.115 & -0.010 & 1.566 & 0.116 & 0.795 & -0.513 & 1.706 & 0.124 & 0.790 & 0.703 & 1.438 & 0.007 & 1.645 & 0.115 & 0.792 & -0.224 & 1.706 & 0.124 & 0.792 \\
\hline $\begin{array}{l}\text { Higher initial trade } \\
\text { deficit }(n \times / y=-.15 \%) 4 /\end{array}$ & 1.071 & -0.179 & 0.073 & 1.566 & 0.130 & 0.802 & -0.739 & 1.706 & 0.142 & 0.797 & 1.040 & 1.704 & 0.097 & 1.648 & 0.129 & 0.799 & -0.256 & 1.706 & 0.142 & 0.799 \\
\hline Benchmark model & 1.052 & -0.163 & -0.021 & 1.567 & 0.130 & 0.802 & -0.842 & 1.706 & 0.142 & 0.797 & 1.012 & 1.738 & 0.004 & 1.648 & 0.129 & 0.798 & -0.364 & 1.706 & 0.142 & 0.798 \\
\hline
\end{tabular}


Table 6: International Tax Competition Games1/

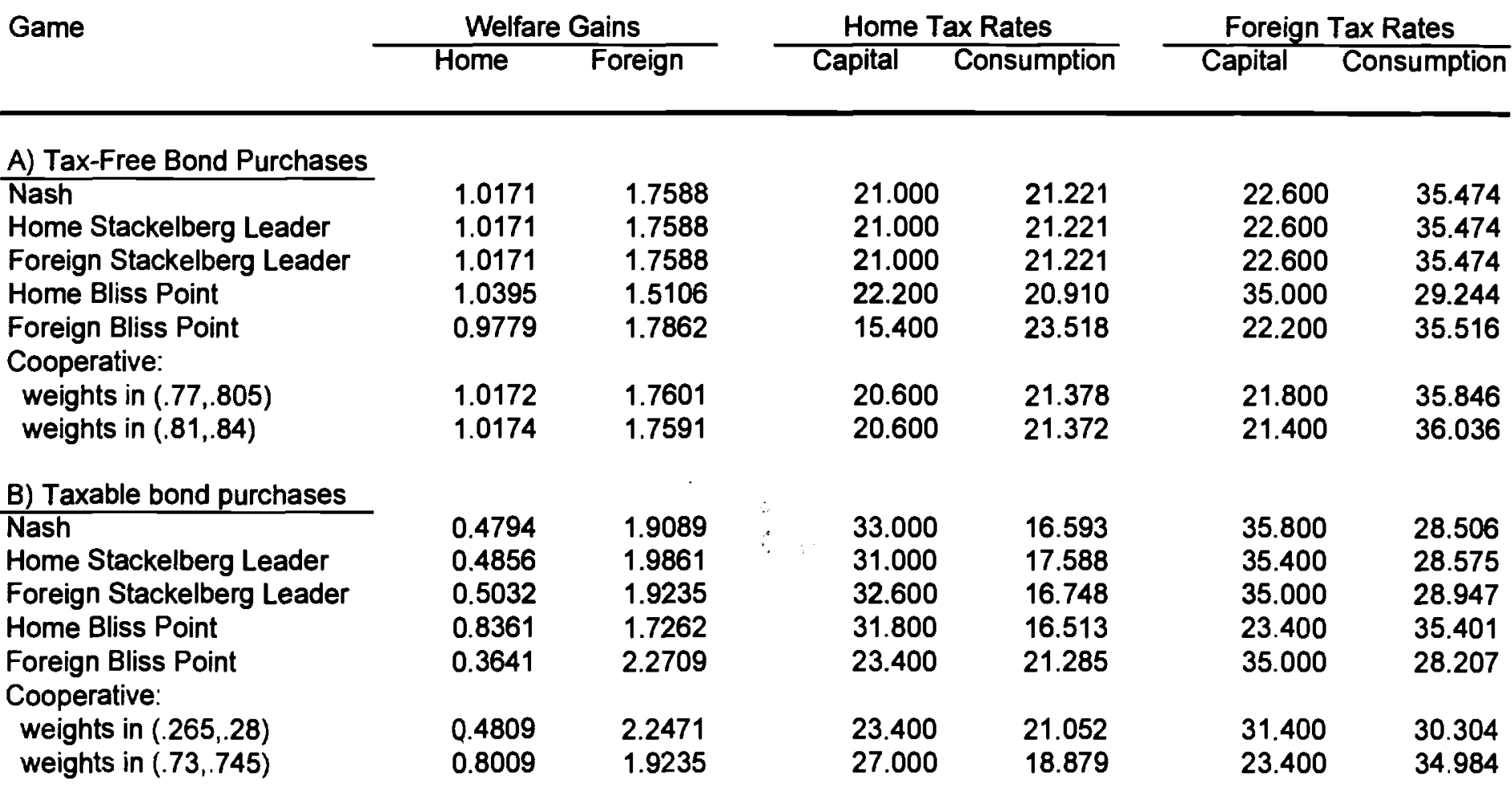

1/Labor tax rates set in each country to the corresponding share of government expenditures in Net Domestic Product (i.e. $t n=23.208$ and $t n^{*}=25.542$ ). All experiments assume that $G$ follows the relative rule in each country and that long-run transfers remain constant as a share of GDP (11 percent in the home country and 18 percent in the foreign country). 
Figure 1

Dynamics of the Capital Stock in the Unilateral Consumption-Only Tax Reform

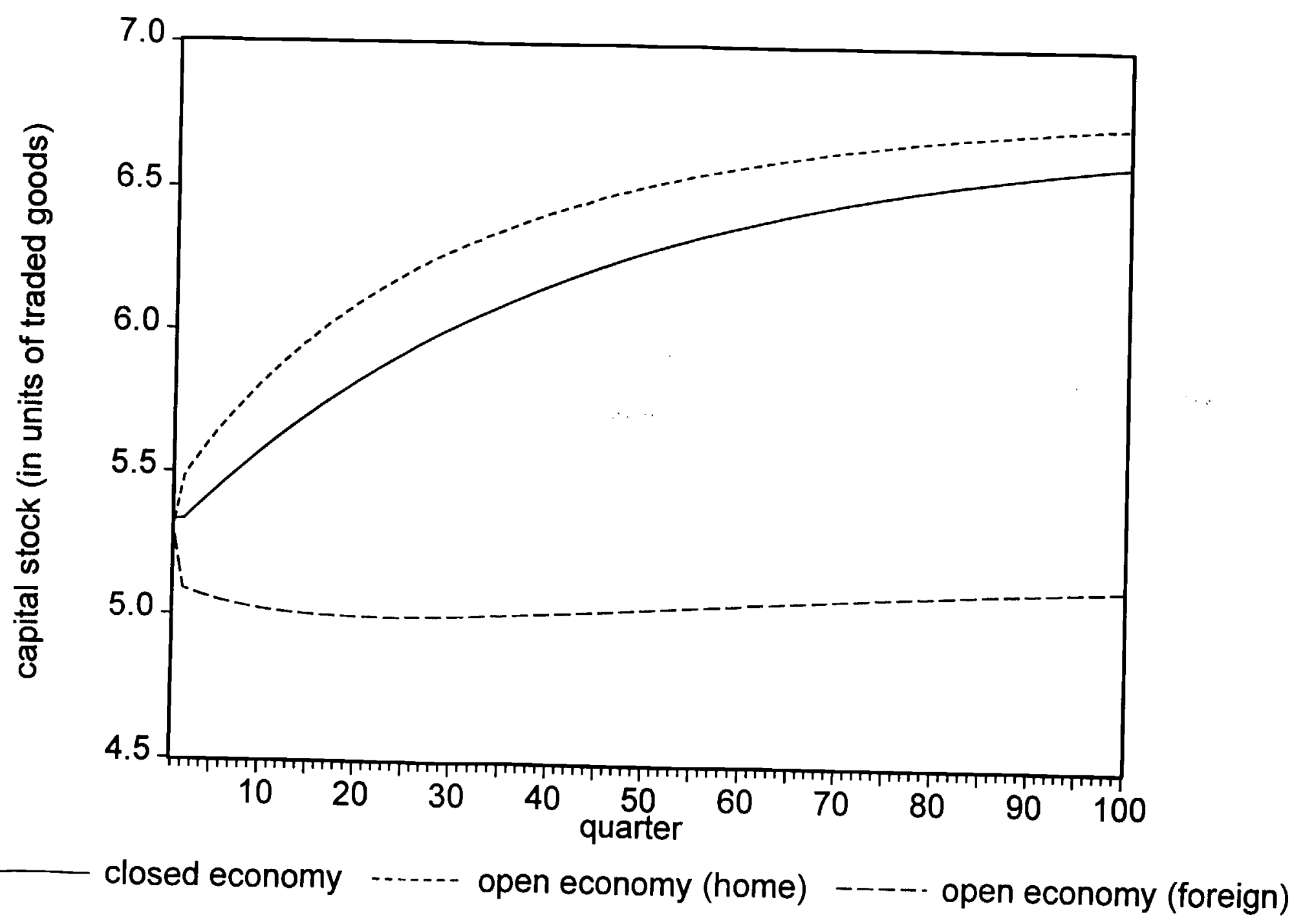


Figure 2

Dynamics of Consumption in the Unilateral Consumption-Only Tax Reform

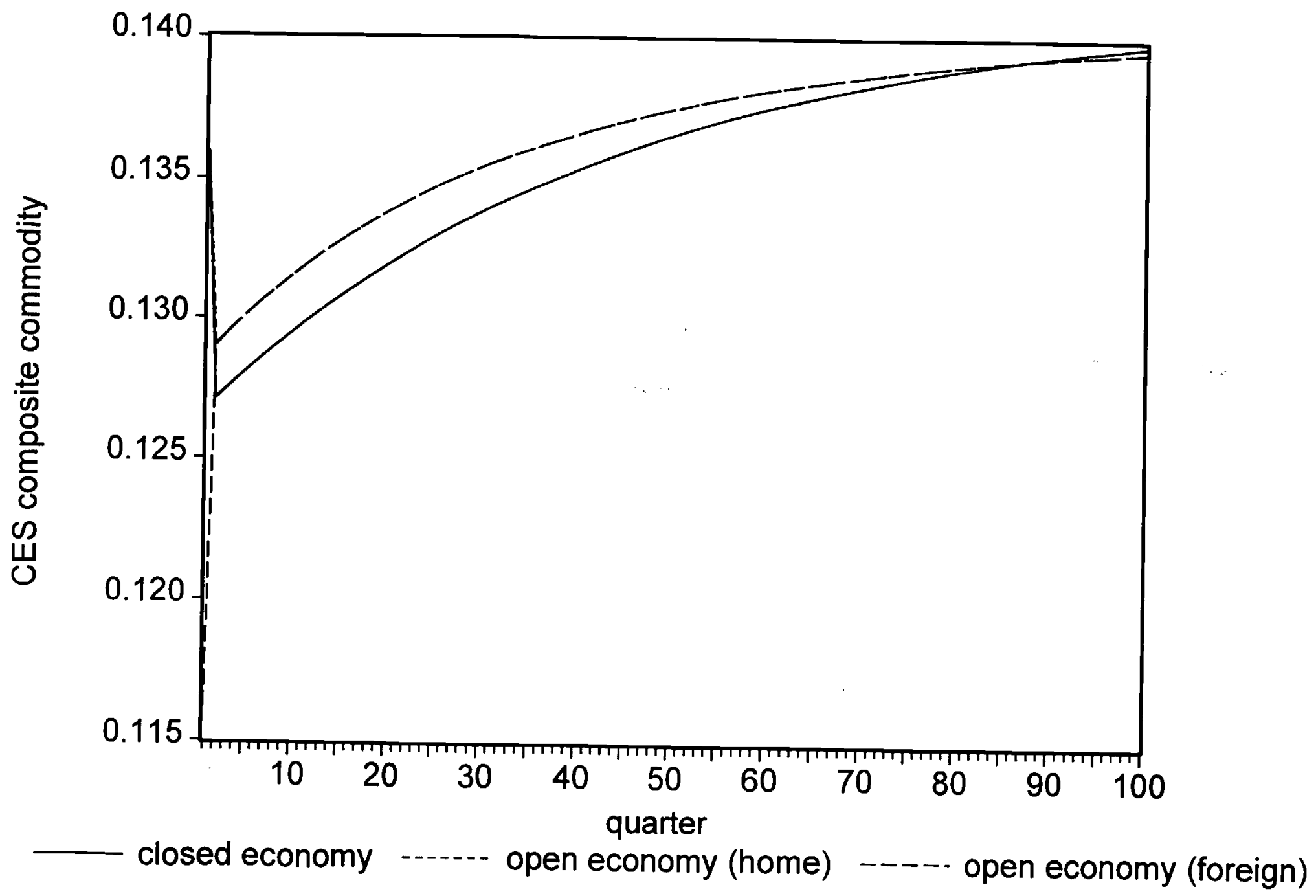


Figure 3

Dynamics of Leisure in the Unilateral Consumption-Only Tax Reform

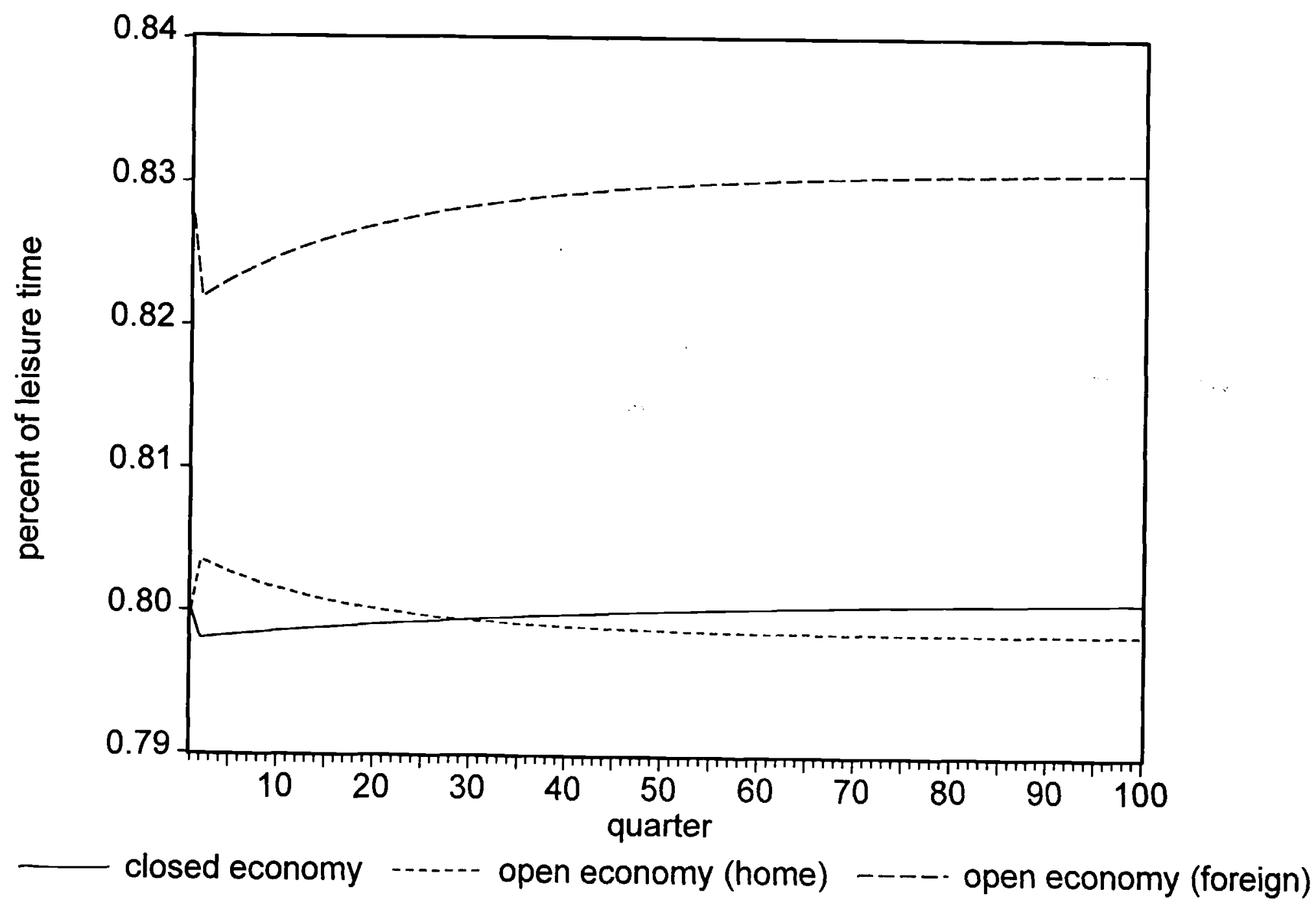


Figure 4

Dynamics of Utility in the Unilateral Consumption-Only Tax Reform

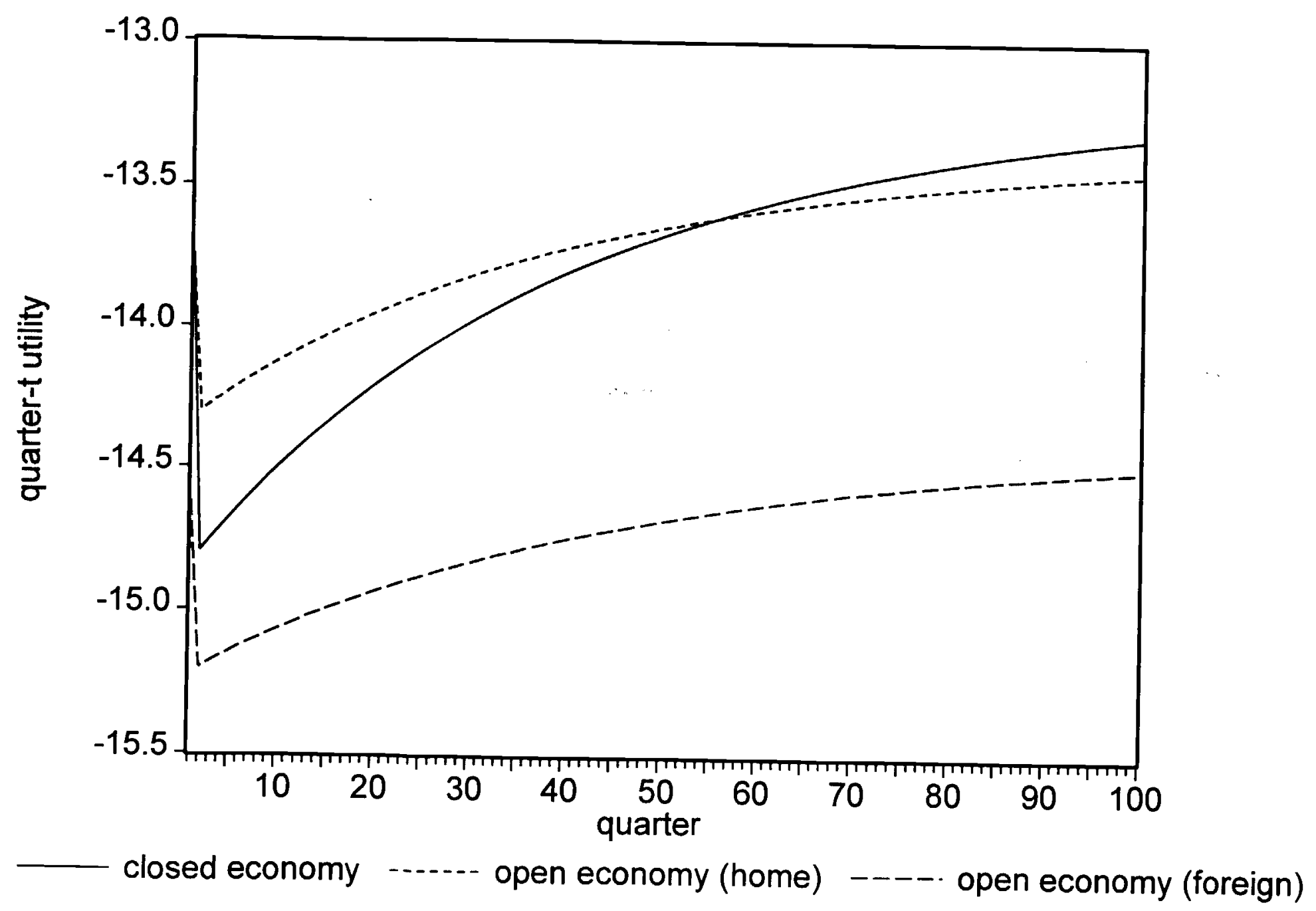


Figure 5

Dynamics of Government Expenditures in the Unilateral Consumption-Only Tax Reform

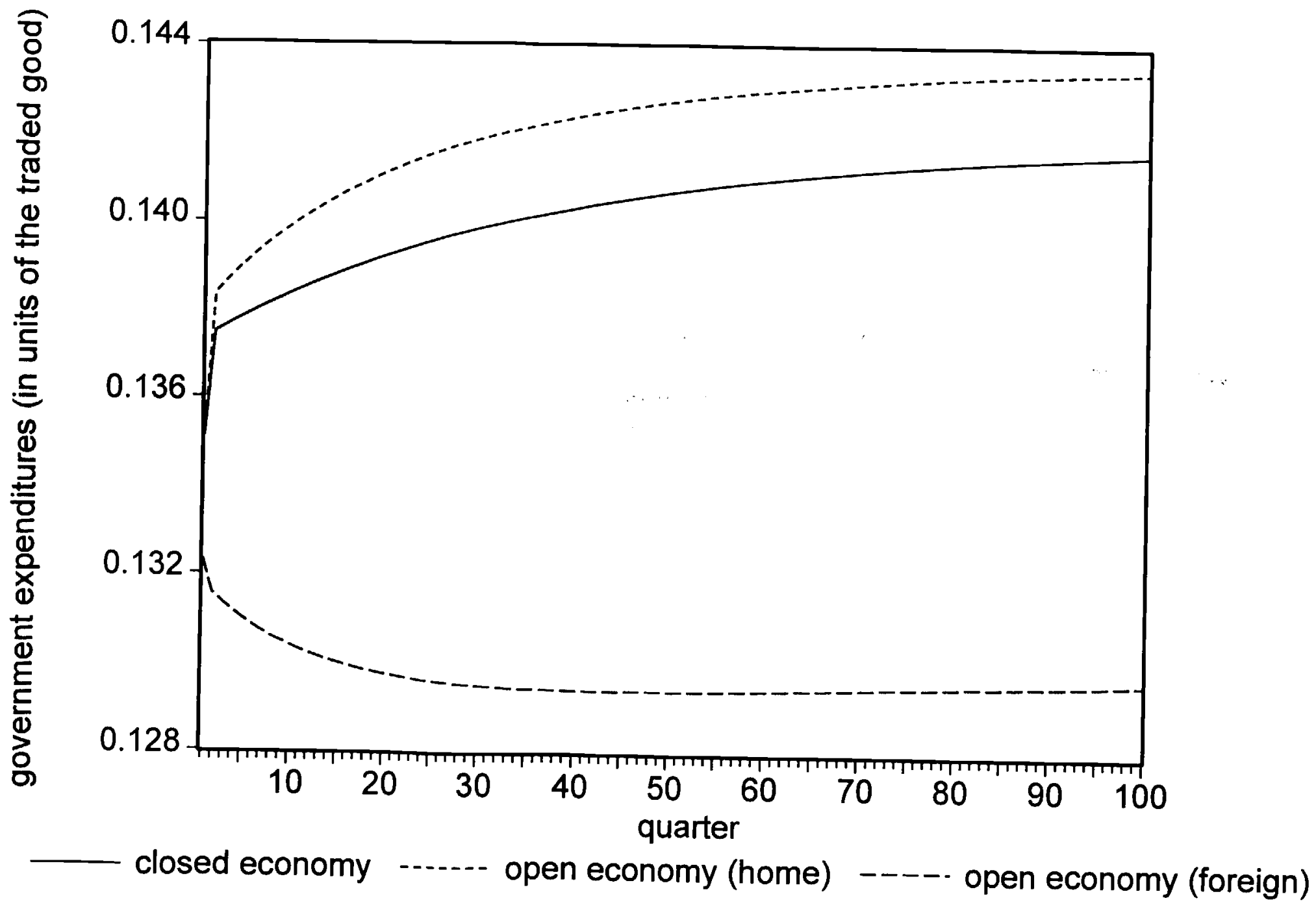


Figure 6

Dynamics of Real Interest Rates in the Unilateral Consumption-Only Tax Reform

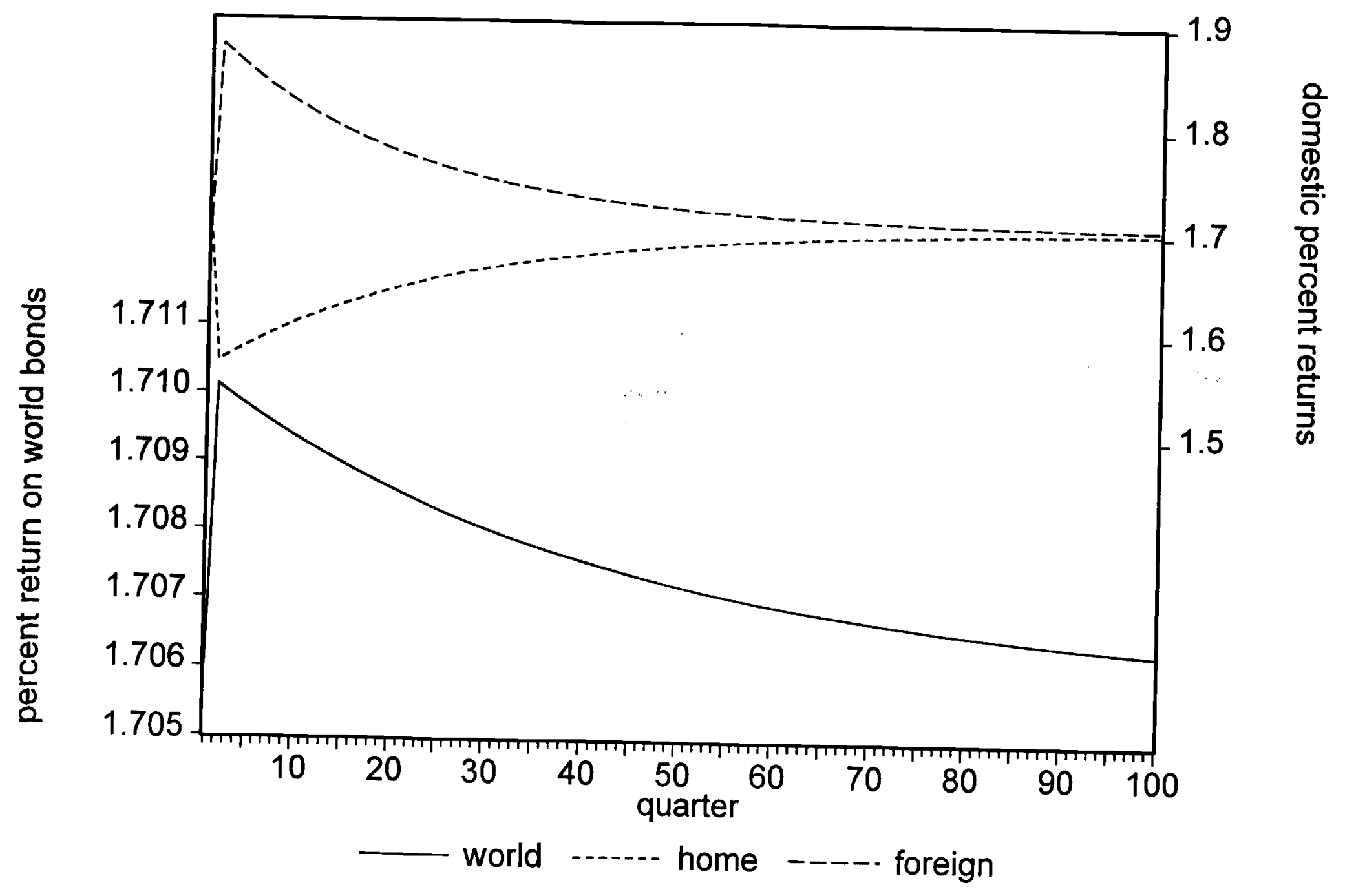


Figure 7

Dynamics of Real Exchange Rates in the Unilateral Consumption-Only Tax Reform

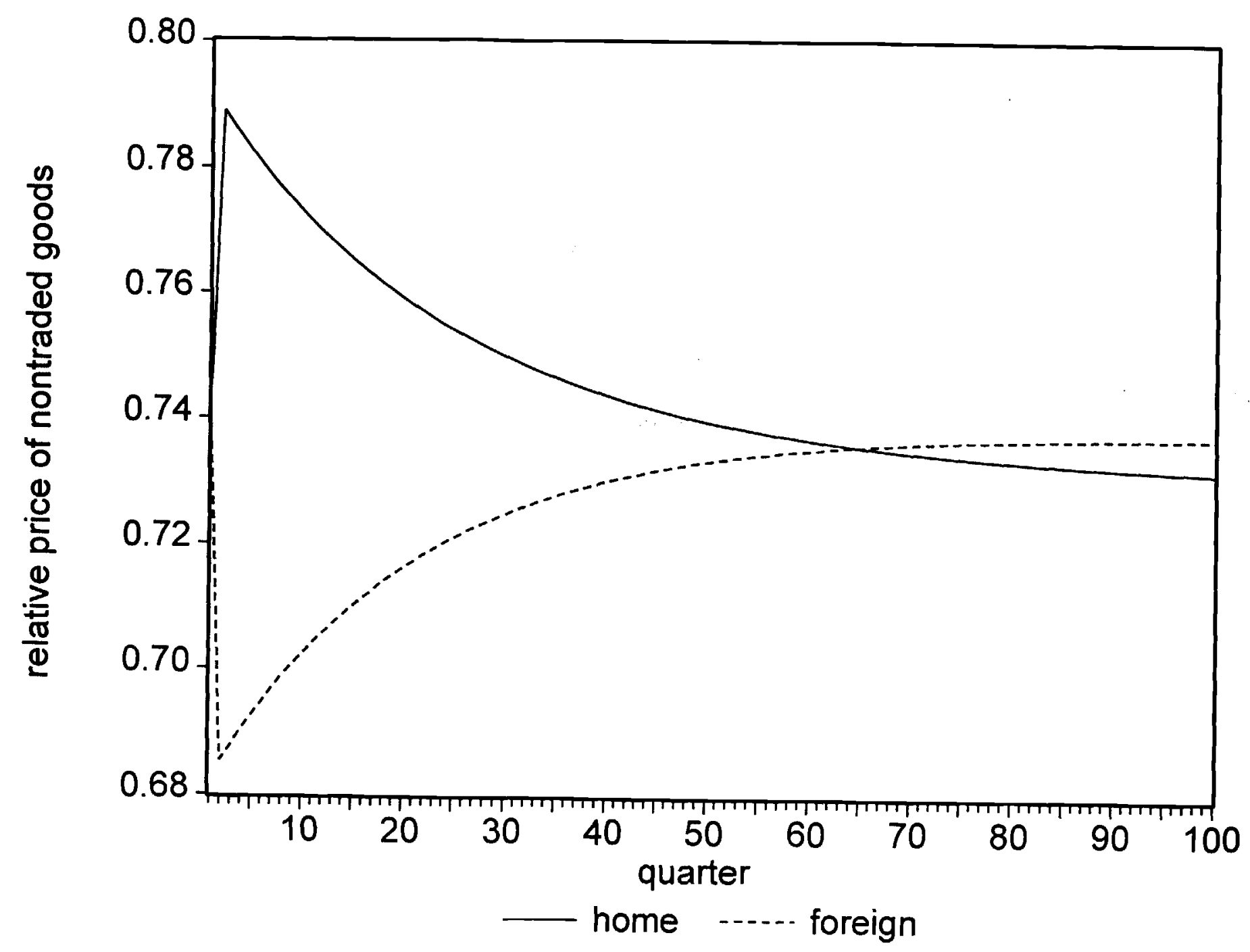


Figure 8

Dynamics of Net Foreign Asset and the Trade Balance in the Unilateral Consumption-Only Tax Reform
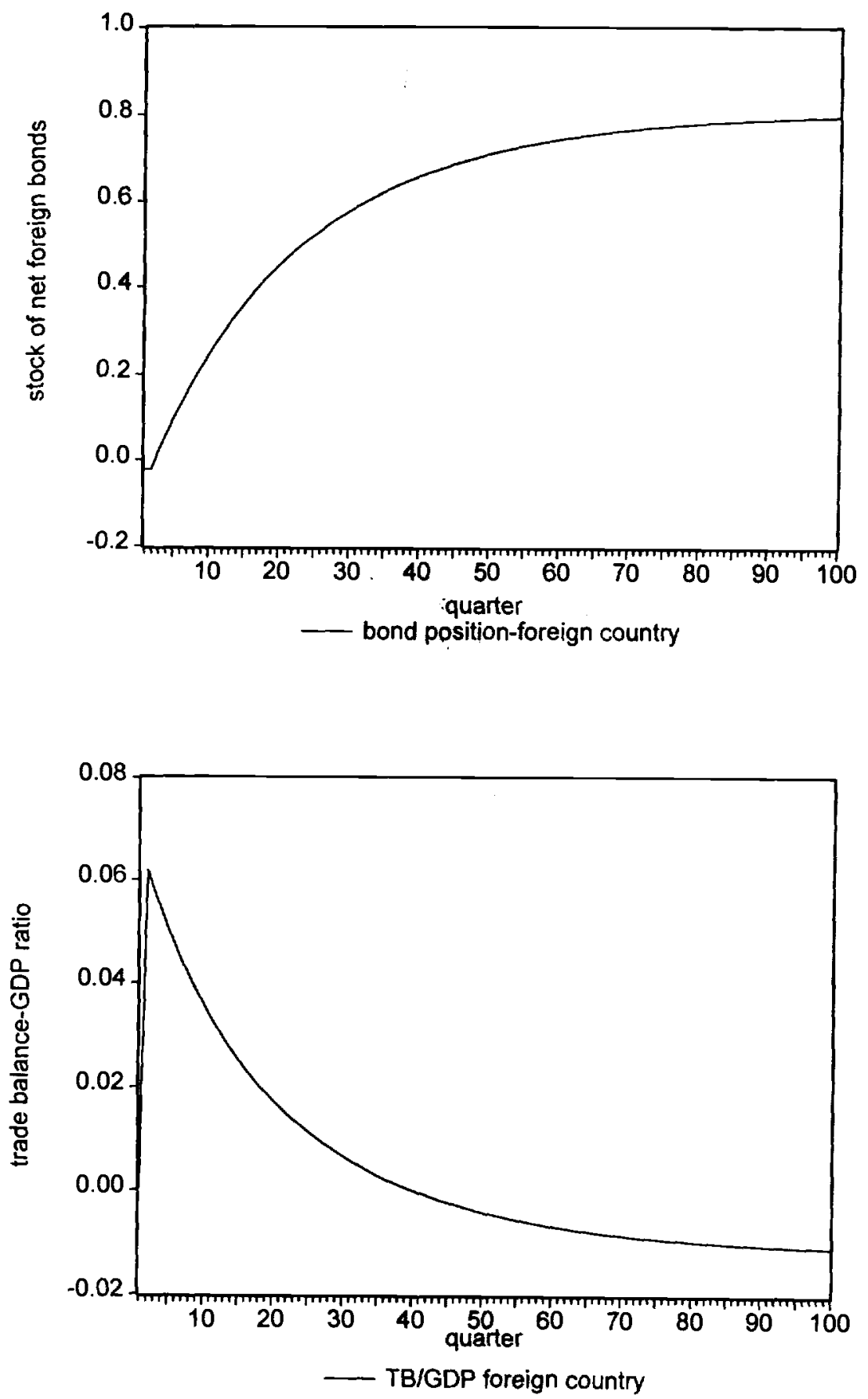


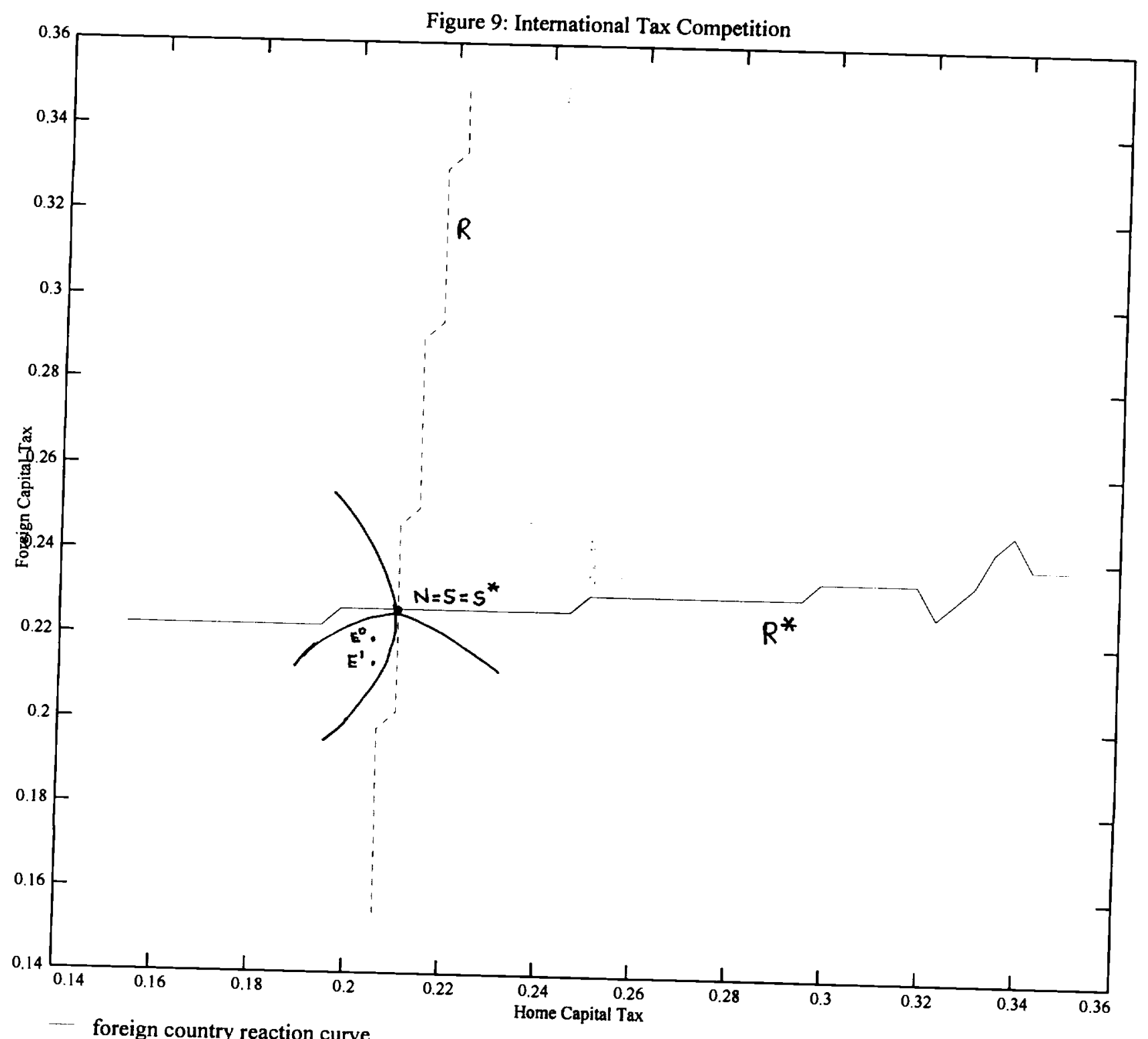

reaction curve

ome country reaction curve 
Figure 10: International Tax Competition

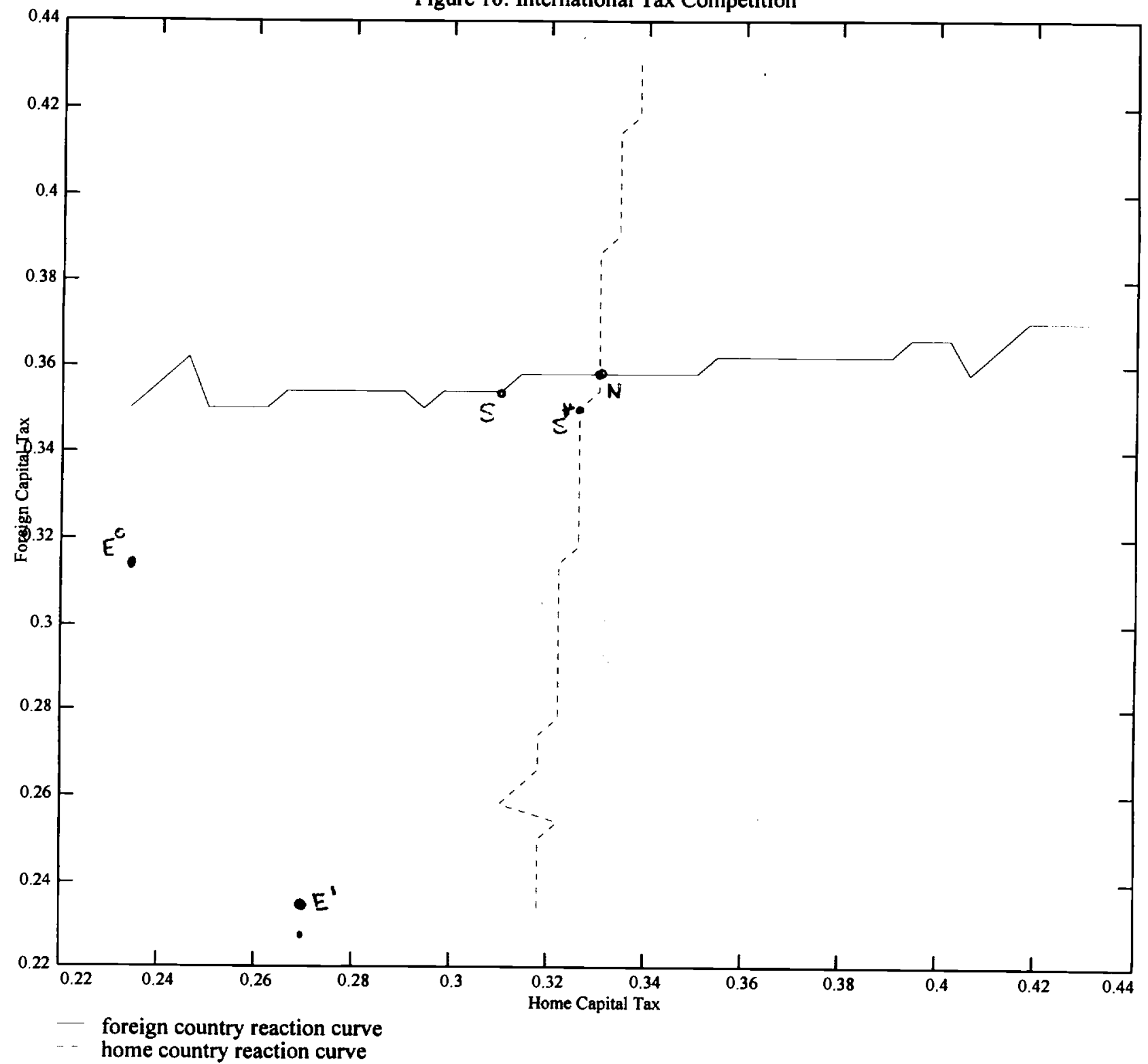

